\title{
Protected Species Bycatch Estimating Approaches: Estimating Harbor Porpoise Bycatch in U.S. Northwestern Atlantic Gillnet Fisheries
}

\author{
Christopher D. Orphanides \\ National Marine Fisheries Service, 28 Tarzwell Drive, \\ Narragansett, RI 02882, USA \\ Email: chris.orphanides@noaa.gov
}

\begin{abstract}
Orphanides, C. D. 2009. Protected species bycatch estimating approaches: estimating harbor porpoise bycatch in U. S. northwestern Atlantic gillnet fisheries. J. Northw. Atl. Fish. Sci., 42: 55-76. doi: $10.2960 / J . v 42 . \mathrm{m} 647$
\end{abstract}

\begin{abstract}
Harbor porpoise bycatch estimates for federally managed gillnet fisheries in northwestern Atlantic US waters were calculated for a nine-year period (1999-2007) using two new methods, and the results were compared to the traditionally used stratified ratio estimation method. The aims of this research were to improve on the existing methods for estimating harbor porpoise bycatch for the Northeast and Mid-Atlantic US gillnet fisheries, to provide insight into the causes of harbor porpoise bycatch, and to compare bycatch estimation techniques that could be applied to other fisheries and species. The new methods included a model approach, and a ratio estimation approach that incorporated variables from both the regression model and the existing ratio estimation method. Initially, bycatch was modeled using a GAM forward stepwise process and included testing numerous variables describing the time, duration, and location of the fishing gear, the fishing gear configuration, and the environmental characteristics of the fished waters. The final model was simplified to a GLM and included variables describing port groupings, seasons, bottom depth, stretched mesh size, and year categories. The new mixed variable ratio estimation approach calculated both the Northeast and Mid-Atlantic bycatch estimates within the same framework by using the port groupings and mesh size variables from the model, and the season variable from the traditional ratio estimating approach. Bycatch estimates for the entire study area were similar between modeling and ratio estimator approaches, though estimates for the two new techniques were more stable from year to year in areas with less observed bycatch. The CVs for the model based estimates were much lower than ratio based estimates, and CVs for the two ratio estimation approaches were similar to each other. However, the model CVs may have been artificially low, as the model may have been over-parameterized in an attempt to accurately calculate annual estimates. Despite some differences, the estimates were not significantly different between approaches for the majority of comparisons.
\end{abstract}

Keywords: Bycatch, bycatch estimates, fisheries, generalized additive models, gillnet, harbor porpoise, marine mammal, Phocoena phocoena, ratio estimators

\section{Introduction}

Humans have become a significant part of the marine ecosystem, and have impacted protected marine populations. This includes direct impacts of whaling (Reeves et al., 2007), ship strikes (NMFS, 2005; Waring et al., 2007), incidental capture in fisheries (Caswell et al.,1998; Read et al., 2006; Baum et al., 2003; Lewison et al., 2004; Bull, 2007), as well as the more difficult to quantify indirect effects of altering abundance of prey, and other species, in the ecosystem (Crowder and Murawski, 1998; Jackson et al., 2001; Myers et al., 2007; Matthiopoulos et al., 2008). Given this complex relationship it is important that human impacts on pro- tected species are quantified with precise and unbiased estimates.

Marine mammals, sea turtles, and sea birds are offered some protection under several national and international laws e.g., CITES, ASCOBANS, ESA, MMPA, MBTA. In the United States, marine mammal bycatch estimates required under the Marine Mammal Protection Act (MMPA) are reported annually in stock assessment reports (SAR) e.g., Waring et al., 2007. Under the MMPA, high bycatch estimates relative to the population size can have a significant impact on fishing activities through enforcement of increased regulations (NMFS, 1998, 2006, 2007a). Thus, another good reason to pro- 
duce precise and unbiased bycatch estimates is to reduce unnecessary regulations. However, estimating bycatch is often difficult due to limited available data, a problem that is not restricted to US waters (Read et al., 2006). In many areas of the world fishing data are sparse, and even in areas where fishing effort and bycatch data are relatively well documented, bycatch events are often rare (Waring et al., 2007), thus making it difficult to accurately estimate bycatch (Dixon et al., 2005). Estimating harbor porpoise (Phocoena phocoena) bycatch in US waters of the Northwestern Atlantic fits this latter scenario, and therefore serves as a good test case to explore methods to estimate bycatch rates of protected species. The general strategies and methodologies explored here may be applied to harbor porpoises in other areas, as well as more generally to other protected species.

Harbor porpoises in the study area are generally found over the continental shelf, and appear to exhibit a north-south seasonal shift in distribution (Palka et al., 1996; Waring et al., 2007). Individual harbor porpoises have been known to exhibit a high degree of variability in their movements (Palka et al., 1996; Read and Westgate, 1997), though generally speaking, study area harbor porpoise are concentrated in the northern Gulf of Maine and Southern Bay of Fundy during the summer months (Gaskin, 1977; Kraus et al., MS 1983; Palka, 1995a, b; Waring et al., 2007). Harbor porpoise distribution extends further south to New Jersey in autumn and spring, and to North Carolina in winter (Waring et al., 2007), though they have been observed throughout the year in the Gulf of Maine. However, knowledge of their distribution, particularly in the winter, is limited by a lack of survey data, and much of their assumed distribution is drawn from bycatch reports.

Harbor porpoises are incidentally caught in the US Northeast and Mid-Atlantic gillnet fisheries, conducted from off the coast of North Carolina, north along the continental shelf, and into to the Gulf of Maine. The Northeast and Mid-Atlantic fisheries are separated at $72^{\circ} 30^{\prime} \mathrm{W}$ longitude, as defined in the NOAA List of Fisheries (NOAA, 2007) (Fig. 1a, b). These gillnet fisheries, which are active all year round, typically use monofilament line with stretched mesh sizes that vary by target species, but do not usually exceed 12 inches. The Northeast fishery is dominated by bottom-tending sink gillnets with stretched mesh sizes ranging typically from 6 to 12 inches (which are used primarily to target monkfish (Lophius americanus) and other groundfish such as Atlantic cod (Gadus morhua) and flounders (e.g., Pseudopleuronectes americanus and Limanda ferruginea). The Mid-Atlantic fishery commonly uses both drift and sink gillnets with stretched mesh sizes typi- cally varying from 2.5 to 12 inches (Waring et al., 2007), and primarily target monkfish, croaker (Micropogonias undulates), weakfish (Cynoscion regalis), striped bass (Morone saxatilis), bluefish (Pomatomus saltatrix), and spiny dogfish (Squalus acanthias). Gillnet string lengths vary regionally and by target species but, in general, are $914 \mathrm{~m}$ (3 000 feet) long and composed of 10 nets, each measuring $91 \mathrm{~m}$ (300 feet).

Regulations to limit harbor porpoise bycatch in these two fisheries were enacted in December of 1998 and include a series of time and area closures, and gear modification areas (Fig. 1). In the Northeast, fishers at particular times and areas are required to have pingers on their nets, and in the Mid-Atlantic, gear modifications regulations are based on mesh size, twine size, float line length, and tie downs (for details on these regulations, see the guides to the Northeast and Mid-Atlantic TRPs on the HPTRT website, hosted by the NOAA Fisheries Service's Protected Resources Division, http://www. nero.noaa.gov/prot\%5Fres/porptrp/).

Total annual harbor porpoise bycatch has previously been estimated using a stratified ratio estimation approach (Smith et al., 1991; Bisack, 1993, 1997, 2003; CUD, 1994; Rossman and Merrick, 1999; Belden et al., 2006; Belden 2007; Belden and Orphanides, 2007). This approach is straightforward and relatively easy to implement and understand, yet it often yields high coefficients of variation (CVs) and may be outdated due to changes in the fishery that have occurred over time.

Few studies have compared bycatch estimating approaches (Diamond, 2003; McCracken, MS 2004; Murray, 2007). This study is aimed to help fill that gap by assessing the previously used stratified ratio estimation approach along with two other approaches: regression modeling and a combined modeling/ratio estimation approach. This research is aimed to improve the existing harbor porpoise bycatch estimation method for the US Northwestern Atlantic gillnet fisheries, and in doing so, provide insight into the causes of harbor porpoise bycatch, and generally evaluate bycatch estimation techniques that could be applied to other fisheries and species.

\section{Data Sources}

Four databases were used to estimate the total harbor porpoise bycatch from 1999 through to 2007: the Northeast Fisheries Observer Program (NEFOP), Allocated commercial landings (Wigley et al., 2008), Northeast Vessel Trip Reports (VTR), and the North Carolina Division of Marine Fisheries (NCDMF) databases. 
The NEFOP database provided data on fishing characteristics from a random sample of the Northeast and Mid-Atlantic gillnet fisheries. These data were used to estimate the observed bycatch rate (observed number of bycaught harbor porpoises per observed effort). All four databases were used to create a complete inventory of fishing effort by trip for the Mid-Atlantic fishery, and all databases except the NCDMF were used for the Northeast fishery. The bycatch rates from the sub-set of these fisheries were then multiplied by the corresponding effort data to estimate total bycatch for both fisheries.

All gillnet gear types present in the NEFOP database were used in the bycatch estimates. Trips from inside bays and sounds were removed from all datasets (NEFOP, Allocated commercial landings, VTR, and NCDMF), as these regions are not managed under the harbor porpoise take reduction plan (HPTRP) because harbor porpoise bycatch there is extremely rare. In addition, all trips during May through December in the MidAtlantic (west of $72^{\circ} 30^{\prime} \mathrm{W}$ ) were removed from all datasets because no harbor porpoise bycatch was observed in this time/area since the observer program was initiated in 1990. For the same reason, all trips during June through November were removed from south of Cape Cod, and east of $72^{\circ} 30^{\prime} \mathrm{W}$.

\section{Observer data}

The NEFOP record information on characteristics of the vessel, crew, trip, haul, gear, and catch (kept, discarded, and incidental bycatch). Further details on data collected by the NEFOP can be found at the NOAA Fisheries NEFSC Fish Sampling website (http://www. nefsc.noaa.gov/fsb/). Rare missing values $(<5 \%$ of all records) for variables in the NEFOP model dataset were filled in with the next best available value. These values were based on a hierarchy of replacement strata as documented in Warden and Orphanides (2008). Environmental variables not collected by the observers, such as bottom slope and surface chlorophyll, were added to each NEFOP record using the methods described in Warden and Orphanides (2008).

The NEFOP has two types of sampling protocols when observing fishing trips: (1) "complete" fish sampled trips where the observer samples the catch for fish discard information (the observer is not able to watch the net as it is being hauled), and (2) "limited" fish sampled trips where the observer watches the net for incidental takes as it is being hauled. All observed bycatch is recorded on both types of trips, though it is assumed that some unknown amount of bycatch could have fallen out of the net while at depth and therefore not observed or recorded on either type of trip. It is also assumed that some bycatch may be missed on "complete" trips since the focus is on processing fish discards and not watching the net as it is hauled in. Thus, "limited" trips were the preferred source of data for estimating harbor porpoise bycatch. However, in the Northeast fishery, hauls observed from both trip sampling protocols were used because in several years the number of "limited" fish sampling trips were few. In the Mid-Atlantic only "limited" trips were used, except during 2007, when the only Mid-Atlantic harbor porpoise bycatch event recorded was during a "complete" trip. For this year only, both "complete" and "limited" trips were used. Dropping "complete" trips (658) from the rest of the sampling period, resulted in removing 9 observed harbor porpoise bycatch events from 8 hauls. It should be noted that this corresponds to the method used to generate the ratio based gillnet harbor porpoise estimates reported in the SARs (Rossman and Merrick, 1999; Waring et al., 2004; Belden et al., 2006; Belden, 2007; Belden and Orphanides, 2007; Waring et al., 2007).

\section{Effort data}

Due to limitations in available reliable data for these gillnet fisheries, the best proxy of effort is the amount of total landings (Orphanides and Palka, 2007; Rossman and Orphanides, 2009). Landings has been shown to be an appropriate unit of effort for harbor porpoise bycatch estimates because total landings have a significant ( $p$ $<0.001$ ) positive relationship with harbor porpoise and no estimating bias when compared against other possible units of effort such as soak duration and gear length (Rossman and Orphanides, 2009) For the Northeast fishery, and for the portion of the Mid-Atlantic fishery that occurs north of North Carolina, VTR landings and Allocated commercial landings were used to estimate total landings, and to provide the location and other fishing characteristic data. VTRs are logbooks that record the amount of landings, location, and a few gear characteristics of each trip. These logbooks are mandatory for vessels participating in any federal fishery.

Northeast Dealer Reports are considered a near census of the amount of catch landed but do not have gear characteristic information. The Allocated commercial landings data merge the VTR logbook and Northeast Dealer Report data by trip, where possible, thus linking gear characteristic information with a near census of landings (Wigely et al., 2008). Where VTR and Allocated trips were successfully matched one to one, the Allocated landings and other characteristics for these trips were used in the analysis. Where the VTR and Allocated trips could not be matched one to one, a proration scheme was used in the analysis, based on strata defined by state, season, and year (as in Belden and Orphanides, 


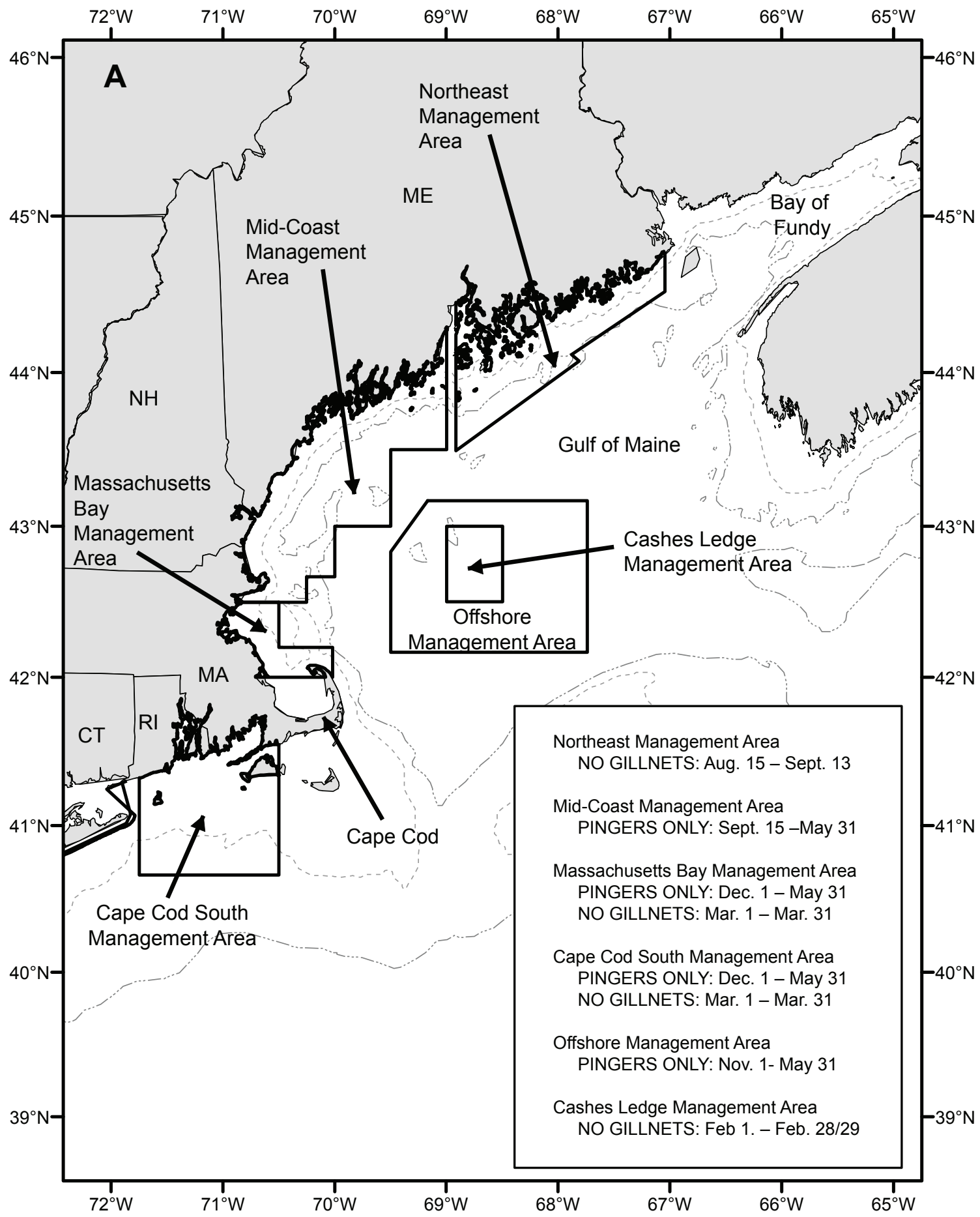

Fig. 1. Gillnet fishery and harbor porpoise management areas for (A) Northeast region and (B) Mid-Atlantic region. Dashed light gray lines depict 50 and 100 meter depth contours. Additional details on gear modification requirements and coordinates of exempted waters can be found at the HPTRP website (www.nero.noaa.gov/porptrp). US states are referenced with their postal abbreviations $(\mathrm{CT}=$ Connecticut, $\mathrm{DE}=$ Delaware, $\mathrm{MA}=$ Massachusetts, $\mathrm{MD}=$ Maryland, $\mathrm{ME}=$ Maine, $\mathrm{NC}=$ North Carolina, $\mathrm{NH}=$ New Hampshire, $\mathrm{NJ}=$ New Jersey, NY = New York, RI $=$ Rhode Island, $\mathrm{SC}=$ South Carolina, and VA = Virginia). 


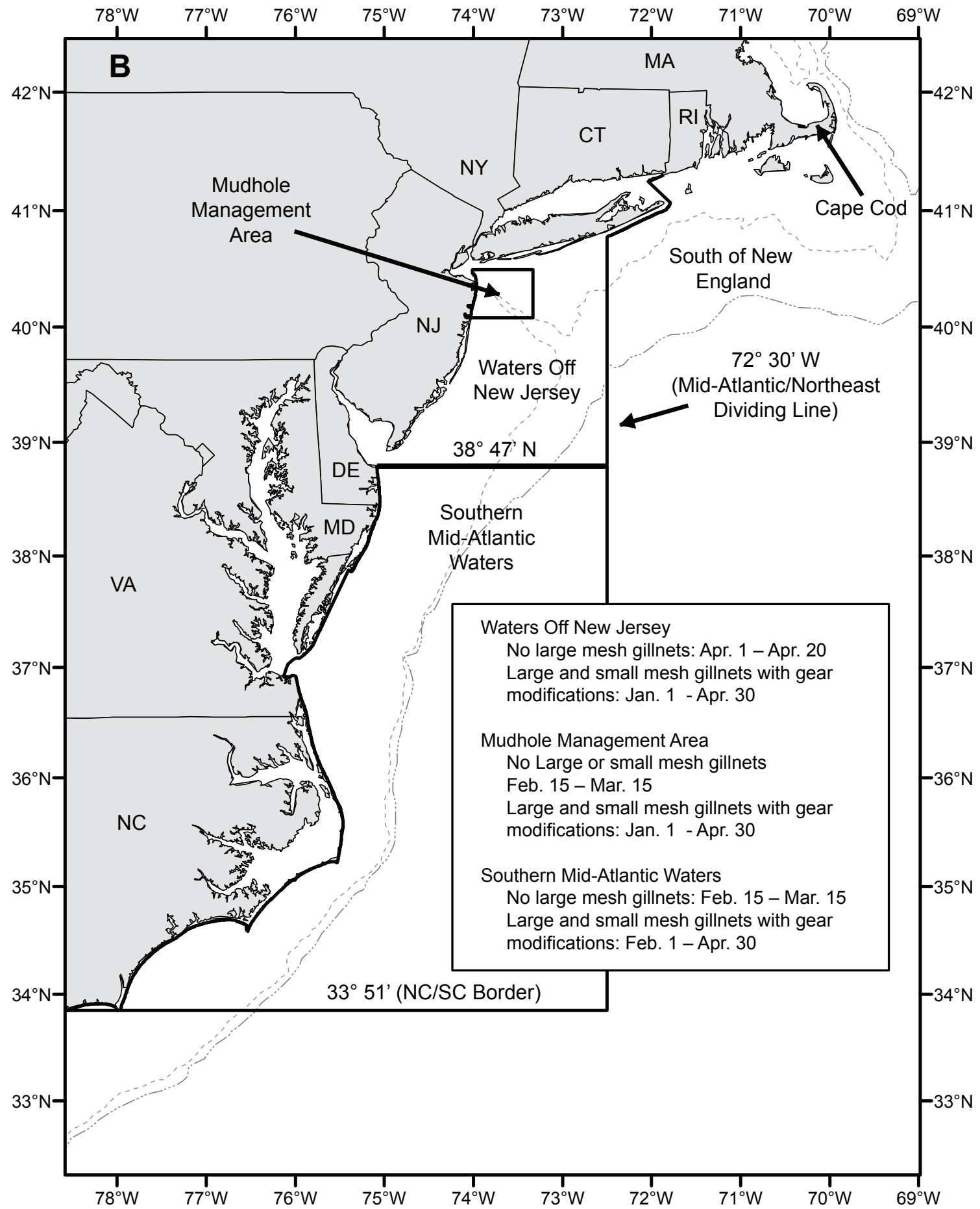

Fig. 1. (Continued) 
2007). That is, for strata where the total Allocated landings were greater than total VTR landings, the landings of each VTR trip in that strata was multiplied by a raising factor that ensured the total VTR landings equaled the total Allocated landings for that strata. Thus, it was assumed that the available VTR trips were representative of the trips that did not provide VTR logbooks or under-reported landings in their VTRs. For strata where the total VTR landings were greater than or equal to the Allocated landings, the landings, location, and gear characteristics from the VTR trips were used. For the modeling estimation approach, effort (landings), location, and other fishing characteristics were required for each individual trip or trip type. Missing values $(<5 \%$ of all observations) in the effort data were filled in a manner similar to the NEFOP data, as were environmental variables (Warden and Orphanides, 2008).

The VTR and Allocated landings data from North Carolina were considered incomplete so NCDMF data were used to estimate total landings from North Carolina gillnet trips. The NCDMF dataset, which is considered a census of the total amount of landings in North Carolina, contains limited fishing characteristics information. The only NCDMF variables that could be used in the analysis were: amount of landings, year, month, and county of port catch were landed in. Without VTR data to provide gear and location information of fishing trips, the NEFOP data were used to provide location and gear information for the North Carolina gillnet fishery. The North Carolina NEFOP data were assumed representative of the North Carolina fishing effort in terms of location of effort and gear configurations. The NCDMF landings were summed by county, month, and year and a raising factor was calculated for each stratum to raise the North Carolina NEFOP landings in the corresponding stratum to the amount recorded by NCDMF. This approach allowed the retention of information on the time, location, gear, and environmental variables associated with the NEFOP data. The resulting effort dataset from North Carolina was combined with the VTR-Allocated effort data from areas north of North Carolina.

\section{Analyses}

Harbor porpoise bycatch rates for 1999-2007 were estimated using three approaches: (a) a regression model, (b) the traditional stratified ratio estimation approach used in past bycatch estimates, and (c) a mixed variable ratio estimation approach. Bycatch rates from each approach were applied to the effort data to estimate total annual and regional harbor porpoise bycatch. For each approach, bycatch estimate CVs were calculated using the standard deviation divided by the actual estimates from 1000 bootstrapped replications with replacement, where trips were the re-sampling unit. The estimates and $\mathrm{CVs}$ from the different approaches were then compared. A number of variables were evaluated for use as the effort variable in the bycatch rate model, but only landings fit both the statistical and practical considerations necessary (Orphanides and Palka, 2007); meaning, only landings had a positive relationship with bycatch and was available in both the bycatch rate and effort datasets.

\section{Regression model approach}

Generalized linear models (GLM), generalized additive models (GAM), and classification trees were used to estimate the harbor porpoise bycatch rate during 1999 through 2007 for the Northeast and Mid-Atlantic gillnet fisheries. The modeling was conducted in S-PLUS 7.0 (Insightful Corp., California, USA). Variables investigated included those describing the time, duration, and location of the gear being fished, fishing gear configurations, and environmental characteristics of the fished waters (Table 1). Variables not included in the effort dataset, but available in the observer dataset, were included in the regression modeling to provide insight into the causes of harbor porpoise bycatch despite being unavailable for estimating total annual bycatch.

Each variable was first investigated individually using GAMs to assess their relationship with harbor porpoise bycatch. Both GAMs and GLMs allow for nonlinear relationships, but a GAM uses smooth functions to replace the linear predictors in a GLM and thus relaxes the parameter assumptions made in a GLM (Hastie and Tibshirani, 1990). Plots of the GAM smooth functions allow easy assessment of the relationships between variables and predictors. Classification trees and GAMs were used to suggest appropriate places to split continuous variables into categorical forms. The GAM and tree results were then assessed relative to relevant knowledge of fishing patterns, harbor porpoise distribution, fishery management, and sample sizes in order to categorize variables. Often times, there were multiple reasonable ways to categorize variables, so several categorical forms of the same variable were included in the modeling process. This allowed the version of the variable that best fit the data to be included in the final model. If the variables selected for the final GAM model are all categorical, then the resulting GAM is functionally the same as a GLM, and thus gains increased simplicity and ease of interpretation.

A GAM forward stepwise selection process was used to select variables to include in the final model. To 
TABLE 1. Base variables investigated for the bycatch model. Additional variables were created by categorizing variables in this table. An * denotes those variables with missing values that were filled in using the process described in Warden and Orphanides (2008).

\begin{tabular}{|c|c|}
\hline Variable Name & Description \\
\hline \multicolumn{2}{|c|}{ LOCATION/TIME VARIABLES } \\
\hline Day of year & Day of year, $1-365 / 366$ \\
\hline Year & Year: 1999 to 2007 \\
\hline \multicolumn{2}{|l|}{ Month } \\
\hline \multicolumn{2}{|l|}{ Seasons } \\
\hline Regions & Regions based on gillnet regulations and fishing effort \\
\hline \multicolumn{2}{|l|}{ Gillnet Management Areas } \\
\hline \multicolumn{2}{|l|}{ Longitude* } \\
\hline \multicolumn{2}{|l|}{ Latitude* } \\
\hline Bottom depth* & Bottom depth (m) \\
\hline \multicolumn{2}{|c|}{ Distance to $50 \mathrm{~m}$ depth contour* } \\
\hline \multicolumn{2}{|c|}{ Distance to $100 \mathrm{~m}$ depth contour* } \\
\hline \multicolumn{2}{|c|}{ Distance to $200 \mathrm{~m}$ depth contour* } \\
\hline \multicolumn{2}{|c|}{ Distance to $500 \mathrm{~m}$ depth contour* } \\
\hline \multicolumn{2}{|c|}{ Distance to the coast $(\mathrm{m})^{*}$} \\
\hline N. Atlantic Oscillation & N. Atlantic Oscillation (NAO) monthly value \\
\hline NAO - 1 & NAO value including a 1 year lag \\
\hline $\mathrm{NAO}-2$ & NAO value including a 2 years lag \\
\hline \multicolumn{2}{|l|}{ Winter NAO } \\
\hline Winter NAO - 1 & Winter NAO monthly value with 1 year lag \\
\hline Winter NAO - 2 & Winter NAO monthly value with 2 years lag \\
\hline $\mathrm{SST}^{*}$ & Sea surface temperature $\left({ }^{\circ} \mathrm{C}\right)$ \\
\hline Bottom water temperature* & Climatological bottom water temperature $\left({ }^{\circ} \mathrm{C}\right)$ \\
\hline \multicolumn{2}{|l|}{ Bottom slope* } \\
\hline Chlorophyll & Chlorophyll $a$ mg/m-3 (from satellite) \\
\hline $\log 10$ (Chlorophyll) & $\log 10$ (Chlorophyll value) (from satellite) \\
\hline Sediment & Type of bottom sediment \\
\hline \multicolumn{2}{|l|}{ FISHING PRACTICES } \\
\hline Soak duration* & Time net in the water (hrs) \\
\hline Regulations compliance & Fishing regulation compliance (e.g., pingers, closures) \\
\hline Target species & Primary species captain aimed to catch \\
\hline \multicolumn{2}{|l|}{ Temporary home port } \\
\hline Port groupings & Port groupings from past harbor porpoise estimates \\
\hline \multicolumn{2}{|l|}{ Vessel gross tonnage } \\
\hline Vessel length & Length of fishing vessel (ft) \\
\hline Haul duration* & Length of time of haul back (hrs) \\
\hline Days absent & Number of days absent from a port \\
\hline State landed & State that catch were landed in \\
\hline Weather & General weather conditions (e.g., clear, partly cloudy) \\
\hline Wave height & Wave height (ft) \\
\hline
\end{tabular}


TABLE 1. (Continued) Base variables investigated for the bycatch model. Additional variables were created by categorizing variables in this table. An * denotes those variables with missing values that were filled in using the process described in Warden and Orphanides (2008).

\begin{tabular}{|c|c|}
\hline Variable Name & Description \\
\hline \multicolumn{2}{|c|}{ GEAR CHARACTERISTICS } \\
\hline Twine size & Thickness of the twine (mm) \\
\hline Pinger use & Whether or not pingers were used \\
\hline Number of pinger used & Total number of pingers used for each string \\
\hline Pinger percentage & Percent of required pingers used $(100 \%=$ full compliance $)$ \\
\hline Mesh count* & Number of meshes in the vertical direction of the net \\
\hline Gear length* & Total length of gear and spaces between nets (ft) \\
\hline Soak hour-feet & Soak duration multiplied by gear length \\
\hline Net height & Height of net (ft) \\
\hline Average mesh size* & Average stretched mesh size (in) \\
\hline Hang ratio* & Ratio of floatline length to stretched net length \\
\hline \multicolumn{2}{|l|}{ Number of nets set } \\
\hline \multicolumn{2}{|l|}{ Number of nets hauled } \\
\hline Used tie downs?* & Were tie downs used: yes, no, unknown \\
\hline Length tie downs & Length of tie downs (ft) \\
\hline Used anchors?* & Were anchors used: yes, no, unknown \\
\hline Number of anchors & Number of anchors used on the string \\
\hline \multicolumn{2}{|l|}{ Type of anchor } \\
\hline Anchor weight & Total weight of anchors (lb) \\
\hline Used additional weights? & Were additional weights used: yes, no, unknown \\
\hline Additional weights & Amount of additional weights used (lb) \\
\hline Used droplines? & Were droplines used: yes, no, unknown \\
\hline Lead line depth & Depth of the net's lead line (fm) \\
\hline Weight of lead line & Total weight of the lead line (lb) \\
\hline Used spaces?* & Were spaces between the nets: yes, no, unknown \\
\hline Space width & Width of spaces between nets \\
\hline Number of spaces & Number of spaces between nets \\
\hline \multicolumn{2}{|l|}{ Color of net } \\
\hline Float distance & Distance between floats \\
\hline \multicolumn{2}{|l|}{ Total number of floats } \\
\hline \multicolumn{2}{|l|}{ OBSERVER PRACTICE } \\
\hline Type of trip & Observer protocol: complete, limited \\
\hline
\end{tabular}

allow modeling of hauls with no landings, 0.001 metric tons were added to the landings from each observed haul, as the model uses a log link and the log of zero is undefined. A quasi-Poisson family distribution was used to account for possible over-dispersion. For each continuous variable, the variable was modeled using a smoother with four degrees of freedom, a simplified smoother with two degrees of freedom, and a linear form. At each step in the stepwise selection process, the Akaike information criterion (AIC) for each form of each variable was evaluated, and used to select the variable for that step. In some cases, the number of parameters in the variable selected, the amount of dispersion, and the practicality of using this variable to get annual estimates were also taken into 
account. The model-based bycatch estimates were evaluated by region and year, through examination of model randomized quantile residuals (Dunn and Smyth, 1996), and the spatial distribution of predicted bycatch.

\section{Traditional stratified ratio approach}

Bycatch rates and their associated CVs were calculated for 2007 using the same general ratio estimation approach that is reported in SARs from 1990-2006 (Smith et al., 1991; Bisack, 1993, 1997; CUD, 1994; Rossman and Merrick, 1999; Waring et al., 2004; Belden et al., 2006; Belden, 2007; Belden and Orphanides, 2007). Annual Northeast fishery data was stratified temporally by season, spatially by port group-area and management areas, and by bycatch avoidance techniques via the use of pingers. Seasons were defined as winter (January to May), summer (June to August), and autumn (September to December). Management areas are illustrated in Fig. 1a. Port groups included: Northern Maine, Southern Maine, New Hampshire, North of Boston, South of Boston, Offshore, East of Cape Cod, and South of Cape Cod. Annual Mid-Atlantic harbor porpoise bycatch estimates were stratified by month and state for much of the time series, and by season and state when the observed annual porpoise bycatch spanned multiple months (Belden and Orphanides, 2007). Observed bycatch rates for each stratum were multiplied by the total effort in the corresponding stratum. Bycatch for each region was then estimated by summing the bycatch of the strata within each region.

\section{Mixed variable ratio approach}

This approach combines the other two approaches. Bycatch rates for 1999-2007 were estimated within strata that were a combination of strata discovered in the modeling approach and in the traditional stratified ratio approach. As in the traditional ratio approach, strata specific bycatch rates were multiplied by the total effort in the corresponding strata, and estimates for each stratum were summed to estimate bycatch for each region. Details on the specific variables used in this stratification approach were considered an outcome of the study, and are therefore reported in the Results section.

\section{Results}

Observed harbor porpoise bycatch from 1999 to 2007 totaled 244 animals out of 43830 observed hauls (0.005 harbor porpoise per haul). Over $99 \%$ of hauls had no harbor porpoise bycatch. Among the hauls that did have harbor porpoise bycatch, 178 hauls $(86 \%)$ had one take, 19 hauls $(9.2 \%)$ had two takes, eight hauls $(3.8 \%)$ had three takes, and only one haul $(0.4 \%)$ had four takes. Most observed bycatch occurred from the waters off New Jersey and further north (Fig. 2a). The majority of takes (231 takes, 94.6\%) occurred from October through May, and the months with the highest number of observed takes were February (55 takes, 22.5\%) and April (44 takes, 18.0\%). NEFOP observed hauls (Fig. 2a) and VTR recorded trips (Fig. 2b) show a similar distribution across much of the continental shelf from the Gulf of Maine through North Carolina.

\section{Regression model approach}

The final model that was selected primarily described bycatch in terms of space and time, plus the inclusion of one gear variable:

$$
\begin{aligned}
& \text { glm }(\text { take } \sim \text { offset }(\log (\text { mtonslanded }))+\text { portcode.c }+ \\
& \text { season.c }+ \text { mesh.c }+ \text { depth.c }+ \text { year.c } \\
& \text { family }=\text { quasi }(\operatorname{link}=\log , \operatorname{var}=\mathrm{mu}))
\end{aligned}
$$

Detailed descriptions of the categorical model variables are provided in Table 2 . In order of selection, the selected variables were port groupings, season, mesh size categories, bottom depth categories, and year groupings (Table 3). GAM plots of the final model (Fig. 3) and the exploratory plots (Fig. 4) show the relationships of these variables to harbor porpoise bycatch rates.

GAM plots of port groupings in the final model show the highest bycatch rates (port groups above the $y=0$ line) with bycatch in the New Hampshire port grouping, and some of the weakest in the North Carolina and Virginia, E. of Cape Cod, and S. of Boston port groups (Fig. 3). These port groupings were created by applying classification tree analysis (Fig. 4) to the port groups used in past Northeast estimates (Bisack, 1997) and Mid-Atlantic states, while still dividing the Northeast and Mid-Atlantic according by $72^{\circ} 30^{\prime} \mathrm{W}$ longitude and attempting to keep some regional continuity.

The season GAM plot from the final model (Fig. 3) and from the exploratory analyses (Fig. 4) shows the highest bycatch rates were during the February/April time period and the lowest bycatch rates were during June-August. This season variable captured similar bycatch months in different areas. For example, the highest bycatch rates period corresponds to peak bycatch rates in the areas off of New Jersey (February in the Mid-Atlantic) and south of New England (February and April in the Northeast).

The mesh size exploratory plot shows a positive trend between mesh size and bycatch (Fig. 4). For the model (Fig. 3), mesh size was divided using a tree into 
three categories at $<6.535,6.535-9.150$, and $>9.150$ inches $(<16.598,16.598-23.241$, and $>23.241 \mathrm{~cm})$ with bycatch rates per metric ton of fish landed increasing with increasing mesh size, from 0.017 to 0.116 to 0.400 , respectively. The exploratory depth plot showed the highest bycatch rate at an intermediate depth (Fig. 4). Depth categories were split using a tree into three categories at $<50.396,50.396-110.864$ and $>110.864 \mathrm{~m}$ with bycatch rates per metric ton of fish landed highest in the middle category (0.302), and lower in the shallower (0.028) and deeper (0.021) categories.

The categorical year variable contains four year categories based on the overall bycatch rate in the study area (Fig. 3). The year categorization was created by grouping years with similar annual overall bycatch rates, thus establishing a straightforward method to apply to future years. Plots of year groupings show the differences in bycatch in the year groupings, and most notably the anomalous year of 2001 (Fig. 3). Compared to other variables in the model, the year variable contributed the least amount towards explaining the bycatch rate (a small percent decrease in model AIC) and resulted in an increase in the estimated dispersion (Table 3). However, it appears to be necessary to account for inter-annual variability and thus allow the model to predict well by year, and to generate reasonable annual estimates which are needed for the SARs.

Additional variables that had a significant relationship to the bycatch rate but were not included in the final model were: sea surface temperature (SST), gear

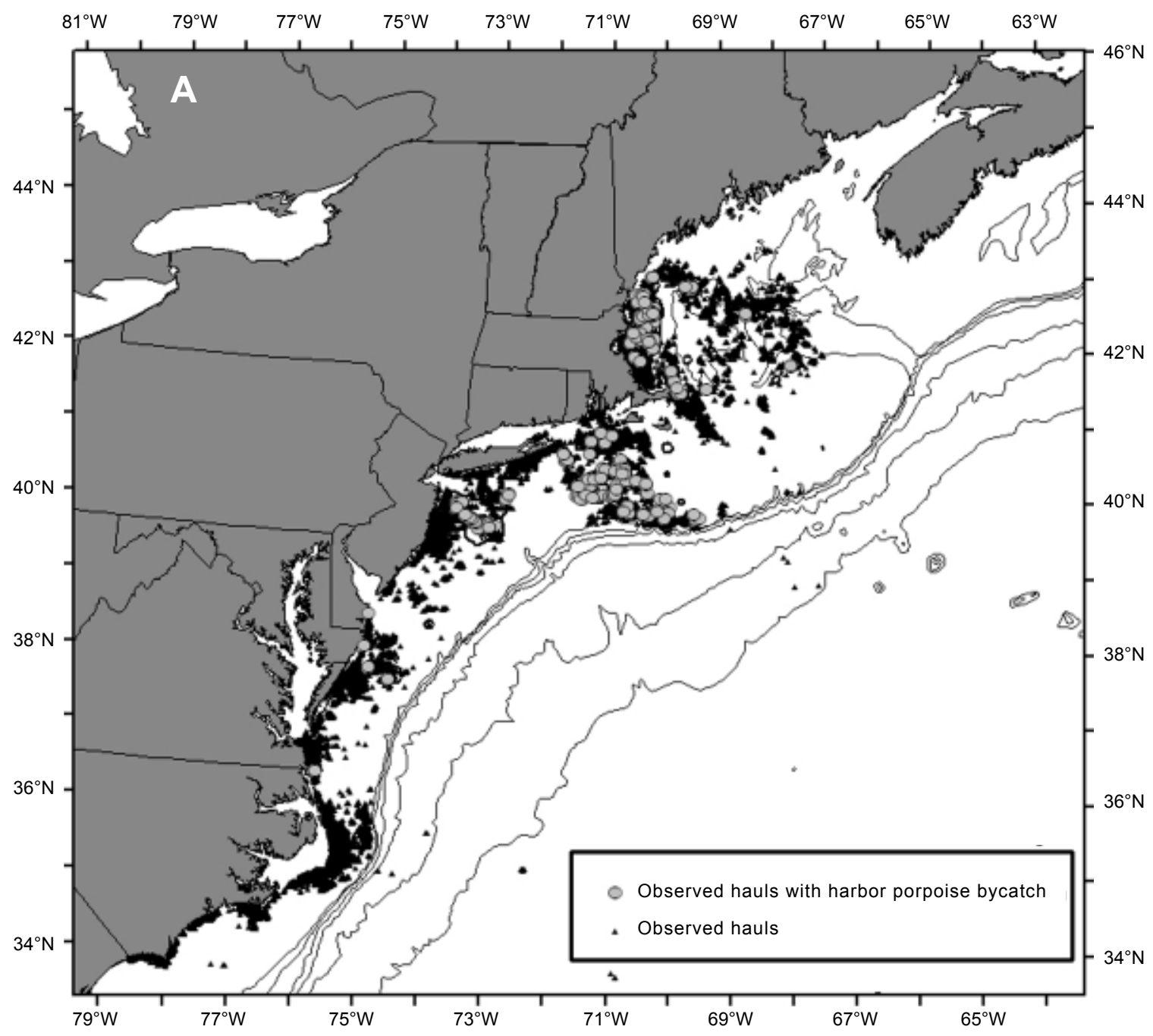

Fig. 2. Maps of (A) Observed hauls and harbor porpoise takes (1999-2007), and (B) VTR gillnet trips summarized by $10 \mathrm{~km}$ cells (1999-2007). 


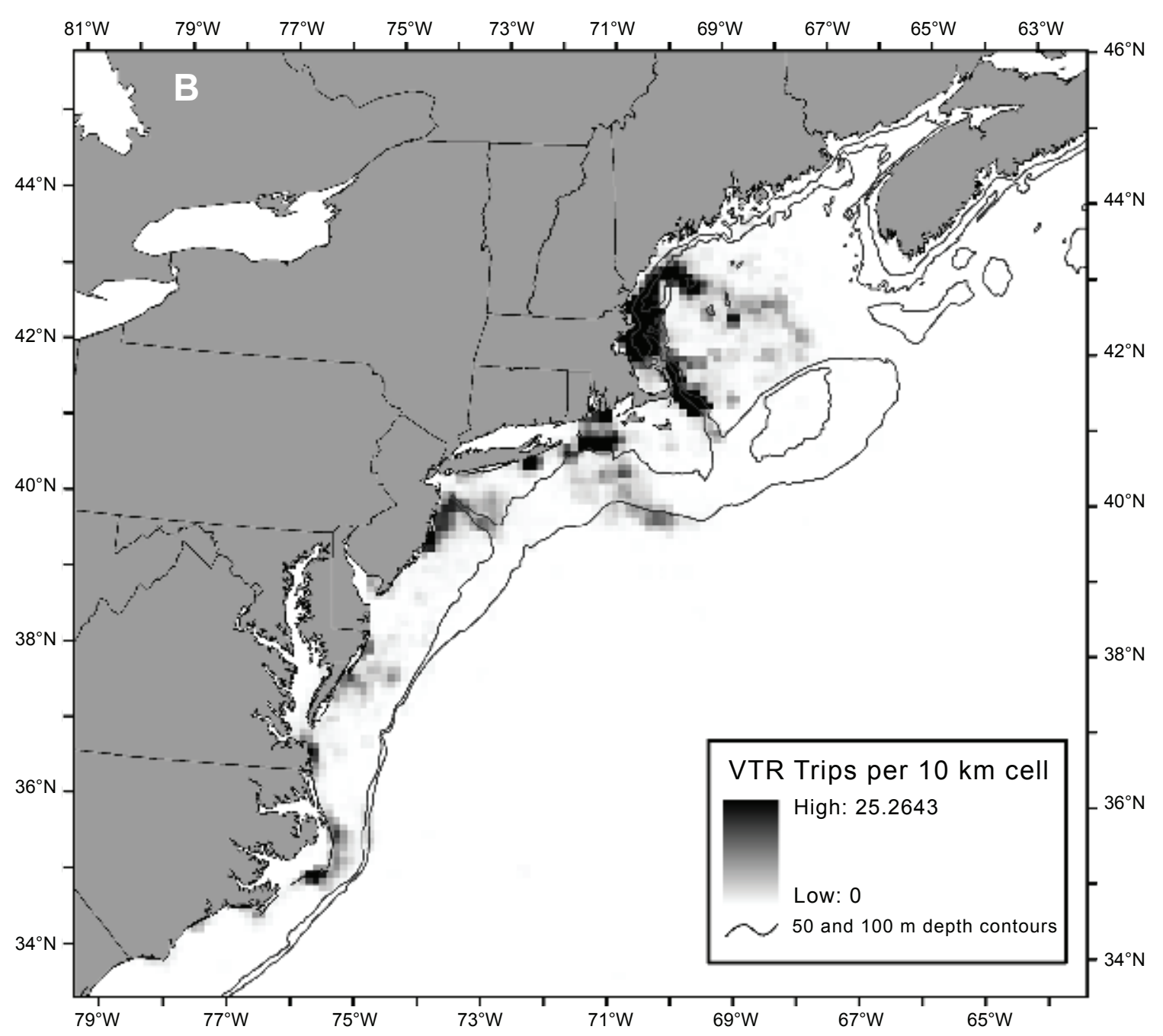

Fig. 2. (Continued)

soak time (hours the net was in the water), and total gear length (in feet) (Fig. 5). These latter two gear variables were particularly important in describing Mid-Atlantic bycatch, but were not reported accurately in the effort data and therefore could not be used to estimate bycatch. Plots of SST show increasing bycatch with colder temperatures. Soak duration and gear length both show positive relationships between increasing bycatch and increasing values, though bycatch decreases somewhat after gear length reaches roughly 6000 feet as the standard error increases dues to smaller sample sizes.

A regression of the predicted bycatch versus actual bycatch by year and region showed a very good match $\left(R^{2}=0.93\right)$ (Fig. 6). In the Southern Mid-Atlantic, the model accurately predicted a small amount of bycatch, though given the limited sample size it was not particularly responsive to matching the exact amount of bycatch in each single year. The model had difficultly distinguishing between the anomalously high bycatch years off New Jersey (2005 and 2006). This resulted in an underestimation of bycatch in this region during 2006. Overall, the model accurately predicted the bycatch in this region. The model predicted well in the Southern New England and Gulf of Maine regions, though predictions in the Gulf of Maine were better in the later portion of the time series than in some earlier years, notably 1999 and 2002. Map of predicted bycatch (Fig. 7) adequately matched the observed pattern for the whole study area (Fig. 2a).

Plots of randomized quantile residuals by latitude and longitude showed no spatial pattern to the residuals 
TABLE 2. Description of unit of effort variable and categorical variables used in Generalized Linear Model (GLM).

\begin{tabular}{|c|c|}
\hline Variables name & Unit of effort and categorical model variable descriptions \\
\hline mtonslanded & Amount of live weight that were landed (in metric tons) plus 0.001 \\
\hline portcode.c & $\begin{array}{l}\text { Port Groupings: (1) North Carolina and Virginia; (2) Maryland, Delaware, New York, } \\
\text { and New Jersey west of } 72^{\circ} 30^{\prime} \text { W longitude; (3) New Jersey, New York, Connecticut, } \\
\text { and the South of Cape Cod port group east of } 72^{\circ} 30^{\prime} \text { W longitude and south of } 41^{\circ} 00^{\prime} \\
\text { N latitude; (4) East of Cape Cod port group north } 41^{\circ} 00^{\prime} \text { latitude; (5) South of Boston } \\
\text { port group; (6) North of Boston port group; (7) New Hampshire port group; and, (8) } \\
\text { combined Southern Maine and Offshore port groups. }\end{array}$ \\
\hline season.c & $\begin{array}{l}\text { Month Groupings: (1) January and May; (2) February and April; (3) March; (4) No- } \\
\text { vember and December; (5) September and October; and (6) June through August. }\end{array}$ \\
\hline mesh.c & $\begin{array}{l}\text { Mesh Size Categories: }(1)<6.535 \text { inches; }(2) \geq 6.535 \text { inches and } \leq 9.150 \text { inches; and } \\
(3)>9.150 \text { inches. }\end{array}$ \\
\hline depth.c & $\begin{array}{l}\text { Bottom Depth Categories: }(1)<50.396 \mathrm{~m} ;(2) \geq 50.396 \mathrm{~m} \text { and } \leq 110.864 \mathrm{~m} \text {; } \\
\text { and }(3)>110.864 \mathrm{~m} .\end{array}$ \\
\hline year.c & $\begin{array}{l}\text { Year Groupings: (1) 2001; (2) } 2005 \text { and 2006; (3) 1999, 2000, and 2003; and (4) 2002, } \\
\text { 2004, and } 2007\end{array}$ \\
\hline
\end{tabular}

TABLE 3. General Linear Model (GLM) stepwise model description output.

\begin{tabular}{lccccc}
\hline \hline & No. of & & & & \\
Variables included in model & Parameters & AIC & Delta AIC & Delta AIC \% & Dispersion \\
\hline Null & 1 & 2389 & & & 7.2 \\
portcode.c & 8 & 2086 & 304 & 12.7 & 7.1 \\
portcode.c + season.c & 13 & 1994 & 92 & 4.4 & 5.3 \\
portcode.c + season.c + mesh.c & 15 & 1873 & 121 & 6.1 & 3.7 \\
portcode.c + season.c + mesh.c + depth.c & 17 & 1808 & 64 & 3.4 & 3.0 \\
portcode.c + season.c + mesh.c + depth.c + year.c & 20 & 1780 & 29 & 1.6 & 4.0 \\
\hline
\end{tabular}

(Fig. 8). QQ-plots of the randomized quantile residuals showed a normal distribution with a few outliers at the top of the distribution, which were hauls with multiple takes (Fig. 9). A histogram (not shown) of these randomized quantile residuals shows a normal bell-shaped distribution with a longer, but nearly unnoticeable tail to the right, where this tail corresponds to the few outliers shown in QQ-residual plots. This tail and the outliers in the QQ-plots are likely due to the fact that the observed data had as many as 4 takes per haul, while the maximum predicted bycatch was about 1.5 takes on a haul. Though the model was able to predict the total bycatch well by time and area, it was not able to capture the full Poisson distribution on a haul-by-haul basis due to the rare instances of hauls that had bycatch of more than two harbor porpoise per haul.

\section{Traditional stratified ratio approach}

The 1999 through 2006 harbor porpoise bycatch estimates using this approach have been reported in other documents (Rossman and Merrick, 1999; Waring et al., 2004; Belden et al., 2006; Belden, 2007; Belden and Orphanides, 2007). The 2007 Northeast bycatch estimate is $395(\mathrm{CV}=0.37)$, and the 2007 Mid-Atlantic bycatch is $58(\mathrm{CV}=1.03)$. Total annual bycatch estimates for all years are shown in Fig. 10, and CVs in Table 4.

\section{Mixed variable ratio approach}

The mixed variable ratio estimate combined the port groupings and the mesh categories from the modeling approach with the season categories (January to May, June to August, and September to December) from 

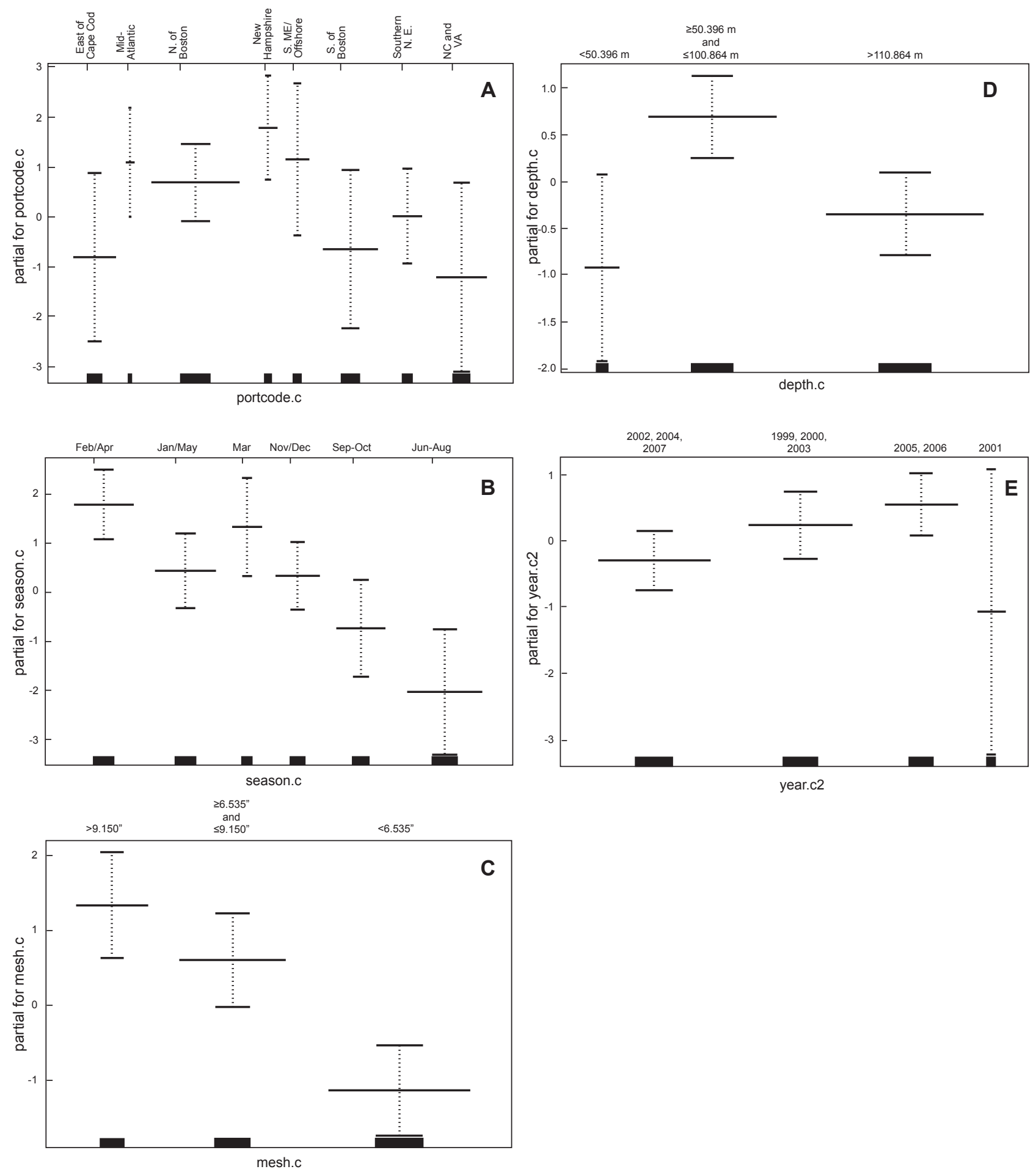

Fig. 3. GAM plots of the categorical variables used in the model (A) portcode.c, (B) season.c, (C) mesh.c, (D) depth.c, and (E) year.c, representing port group, season, mesh size, bottom depth, and year categories, respectively. The zero value on the $y$-axes represents an average bycatch rate of the plotted variable when accounting for the effect of other variables in the model. Areas above this line represent above average bycatch rates, while areas below zero on the $y$-axes represent below average bycatch rates. Note: Mid-Atlantic includes Maryland, Delaware, New York, and New Jersey effort west of $72^{\circ} 30^{\prime} \mathrm{W}$ longitude; Southern N.E includes New Jersey, New York, Connecticut, Rhode Island, and Massachusetts effort east of $72^{\circ} 30^{\prime} \mathrm{W}$ longitude and south of $41^{\circ} 00^{\prime} \mathrm{N}$ latitude. Port grouping abbreviations include $\mathrm{NC}=$ North Carolina, $\mathrm{S} . \mathrm{ME}=\mathrm{Southern}$ Maine, Southern N.E. = Southern New England, and VA = Virginia. 

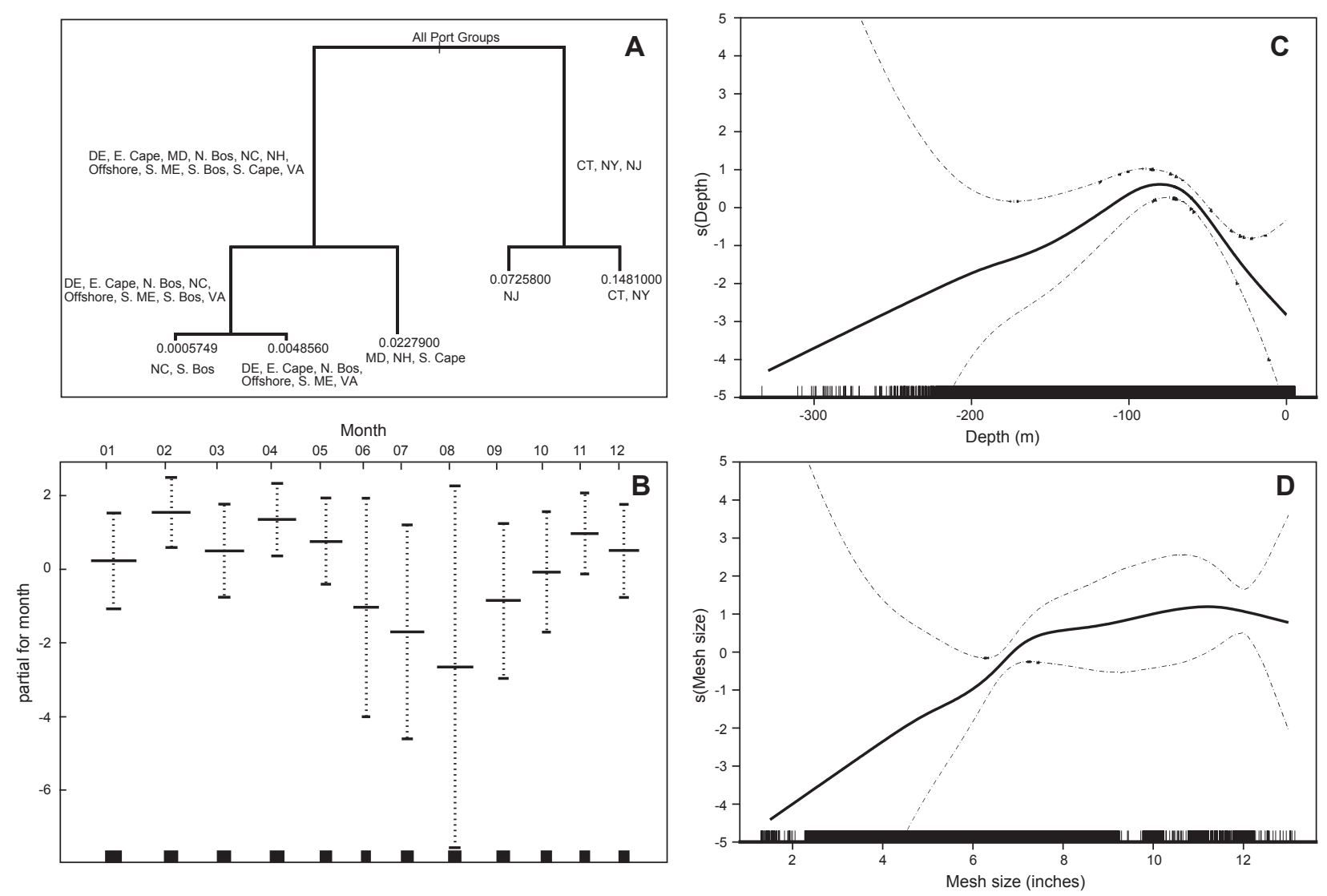

Fig. 4. (A) Classification tree for port groups, and GAM plots for (B) month, (C) depth, and (D) mesh size. The zero value on the GAM plot $y$-axes represents an average bycatch rate. Areas above this line represent above average bycatch rates, while areas below zero on the $y$-axes represent below average bycatch rates. For the classification tree, bycatch rates are shown per haul. For depth and mesh GAM plots, the $y$-axes have been reduced to better show the trends. As a result, the complete standard error range (dotted lines) for the smaller values on the $x$-axes is not shown. Outliers have also been removed in the depth and mesh plots (deeper than $375 \mathrm{~m}$ and mesh larger than 14 inches) to better illustrate trends for the majority of the data.

the traditional stratified ratio approach. The model port groupings were included in this new ratio estimation approach so that the Mid-Atlantic and Northeast bycatch estimates could be calculated within the same analytical framework. In addition, the model port groupings for the Mid-Atlantic region should provide more robust estimates through gains in sample sizes by grouping areas with similar bycatch rates. When the traditional approach was first implemented, individual state strata were used because it was not known how Mid-Atlantic bycatch rates varied throughout the region. The use of pingers is a variable used in the traditional stratified ratio approach. However, this variable was not selected in the bycatch rate model, so it was not used in the mixed variable ratio approach. The mesh size categorical variable, the only gear variable selected in the model, was used in the mixed variable ratio approach. The season categories used in the traditional stratified ratio estima- tion approach were used in the new mixed approach instead of the model derived season categories in order to limit the number of parameters in the estimating process and to use categories that are easier to understand, while still representing temporal variation. By combining the model port grouping, mesh size, and traditional season variables in the new mixed ratio estimation approach, the general spatial-temporal patterns associated with bycatch are represented as well as the dominant gear characteristic. The depth variable was not included in the mixed ratio approach to limit the number of parameters and because depth was not as highly related to the bycatch rate as the other variables used in this approach. The year variable was not required in this approach because the effect of year was automatically taken into account by calculating annual estimates. For the 2002 Northeast estimates, two strata were modified slightly to avoid an unrepresentative estimate due to a small sample 

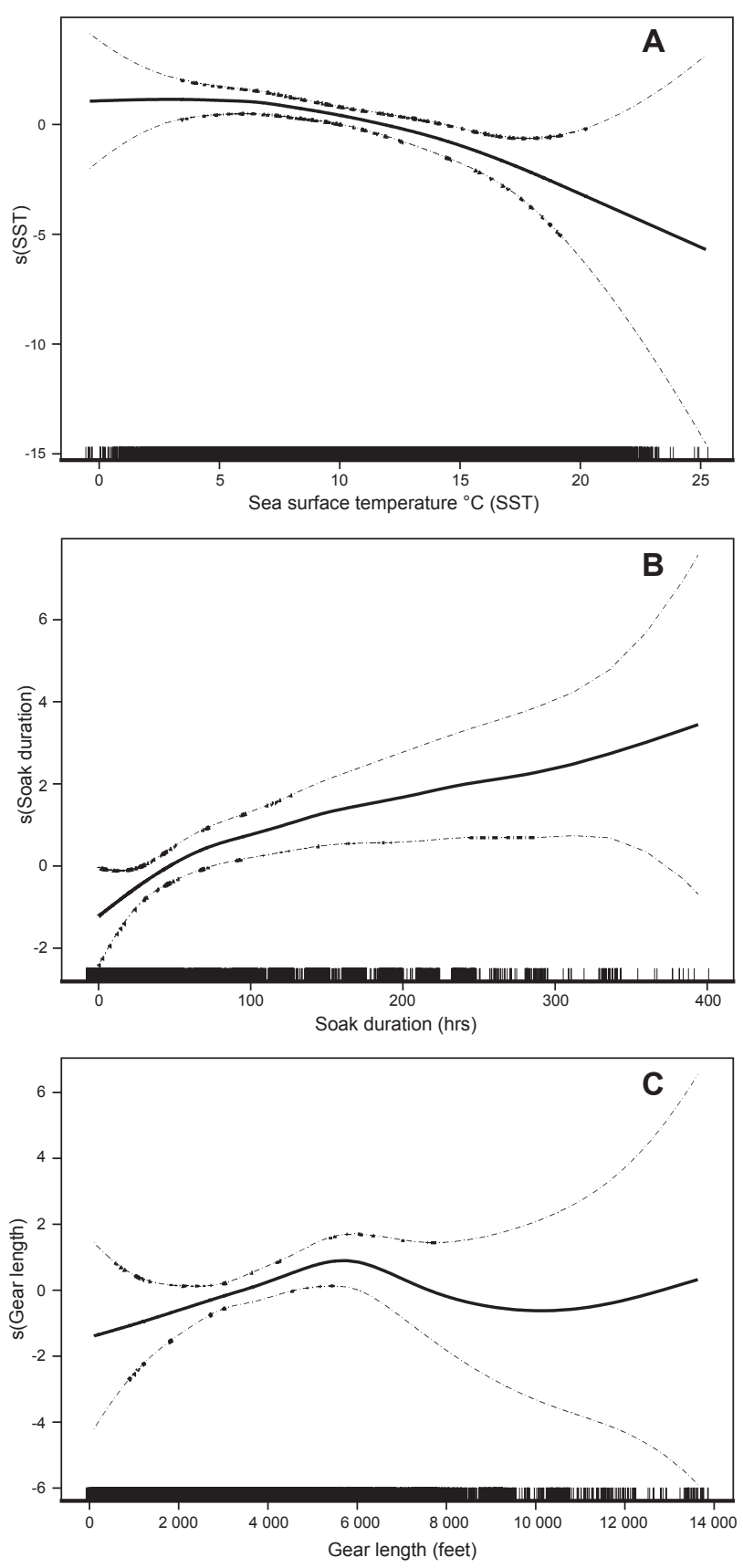

Fig. 5. GAM plots of (A) Sea Surface Temperature, (B) soak duration, and $(\mathbf{C})$ gear length (variables not in the model). The zero value on the $y$-axes represents an average bycatch rate. Areas above this line represent above average bycatch rates, while areas below zero on the $y$-axes represent below average bycatch rates. Note: soak duration and gear length outliers have been removed in order to better visualize the dominant trends (greater than 500 hours soak duration and 15000 feet of total gear length).

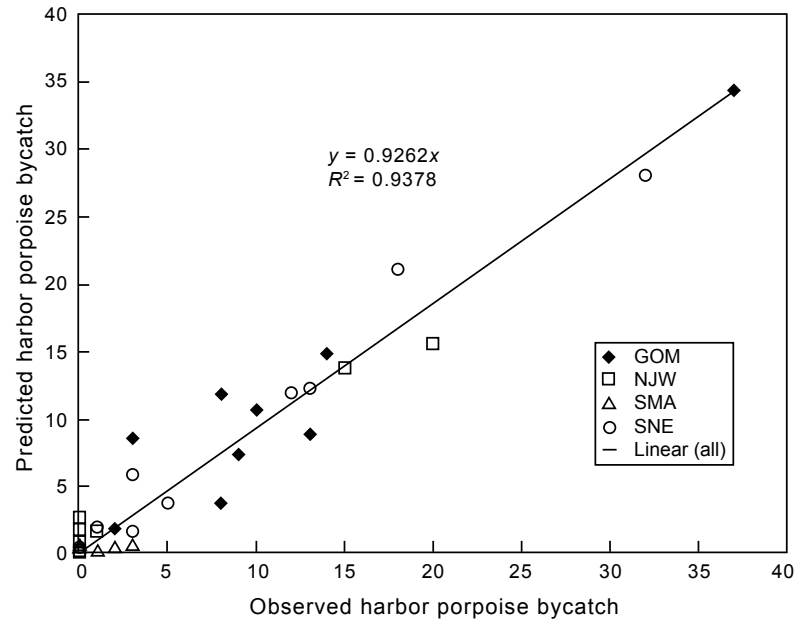

Fig. 6. Observed bycatch vs. predicted bycatch, by region and year, with one observation per year-region combination. GOM = Gulf of Maine, NJW $=$ New Jersey Waters, SMA = Southern Mid-Atlantic, and SNE = Southern New England.

size in one stratum (the 2002 fall-New Hampshire-large mesh strata was combined with the fall-New Hampshiremedium mesh strata).

\section{Estimates comparison}

Bycatch estimates for the full study area were similar for the three estimation approaches (Fig. 10). In the Northeast fishery the regression model based estimates closely followed the estimates from the traditional stratified ratio approach, though were a little higher from 2004 through 2006. The mixed variable ratio estimation approach in this fishery also generally corresponded to the estimates from the traditional approach, though were lower from 2003 through 2006. In the Mid-Atlantic fishery, all three estimates followed the same general pattern from 2004 through 2007, and the regression model and mixed variable ratio estimates in particular were very similar. During 2005 and 2006 the traditional stratified ratio estimates were considerably higher than the other two approaches. From 1999 through 2001 the mixed variable ratio and traditional ratio estimates were very similar and the regression model estimates were higher during 1999 and 2000. The largest difference between the estimates was the CVs (Table 4). The regression model based CVs were much lower than the ratio estimation approaches. The CVs from the mixed variable ratio estimation approach were generally slightly lower than the traditional stratified ratio approach in recent years and generally higher during earlier years. Despite varia- 


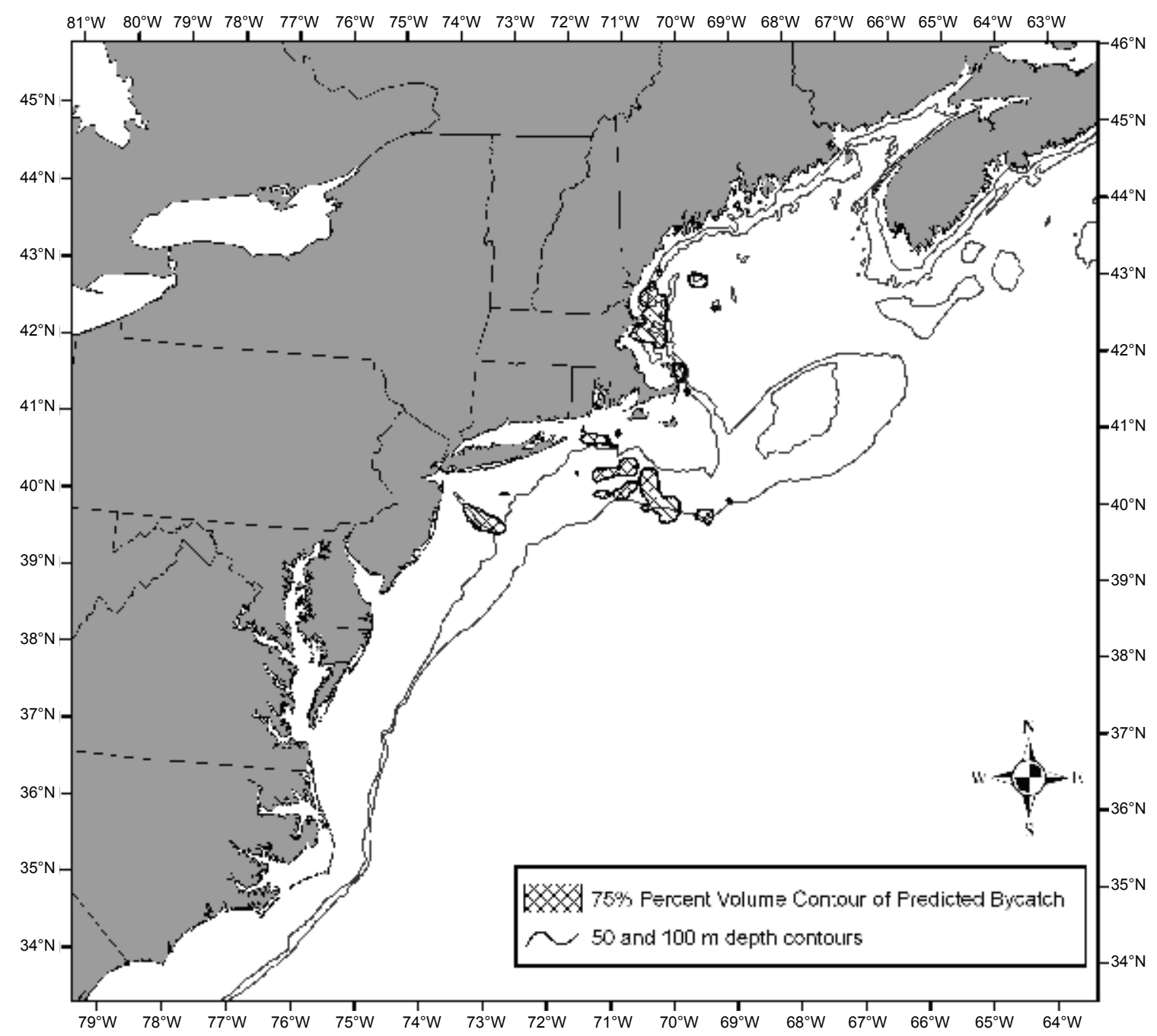

Fig. 7. The $75 \%$ percent volume contour of 1999-2007 model-predicted observed harbor porpoise takes from GLM showing where $75 \%$ of the predicted bycatch is expected to occur.

tion in the point estimates and CVs among approaches, $Z$-tests showed no significant differences in regional annual estimates in the Northeast, and only five significant differences among 24 comparisons in the Mid-Atlantic (Table 5). Four of these five differences in the MidAtlantic occurred when comparing the model approach to the other two approaches in 1999 and 2000 (Table 5).

\section{Discussion}

Development of regression model-based harbor porpoise bycatch estimates provided insight into some of the reasons for bycatch, and suggested ways to improve the ratio estimation approach. The overall congruence between regression model and ratio based estimator approaches validates the estimates derived from both methods. Both the regression model and ratio estimation methods were largely based on time and area strata. The model selection of port groupings as the single best variable to explain the bycatch patterns, followed by a season variable, suggests that the traditional ratio estimation approach and strata definitions based on past fishing and bycatch patterns are not outdated. The selection of these two variables also explains the similarities in the estimates when using the regression model and the traditional stratified ratio approach, particularly for the Northeast region.

The combination of the season and depth variables further suggests harbor porpoise north-south seasonal movements, which interact with the gillnet fisheries, to the largest degree, between the 55 and $110 \mathrm{~m}$ depth con- 

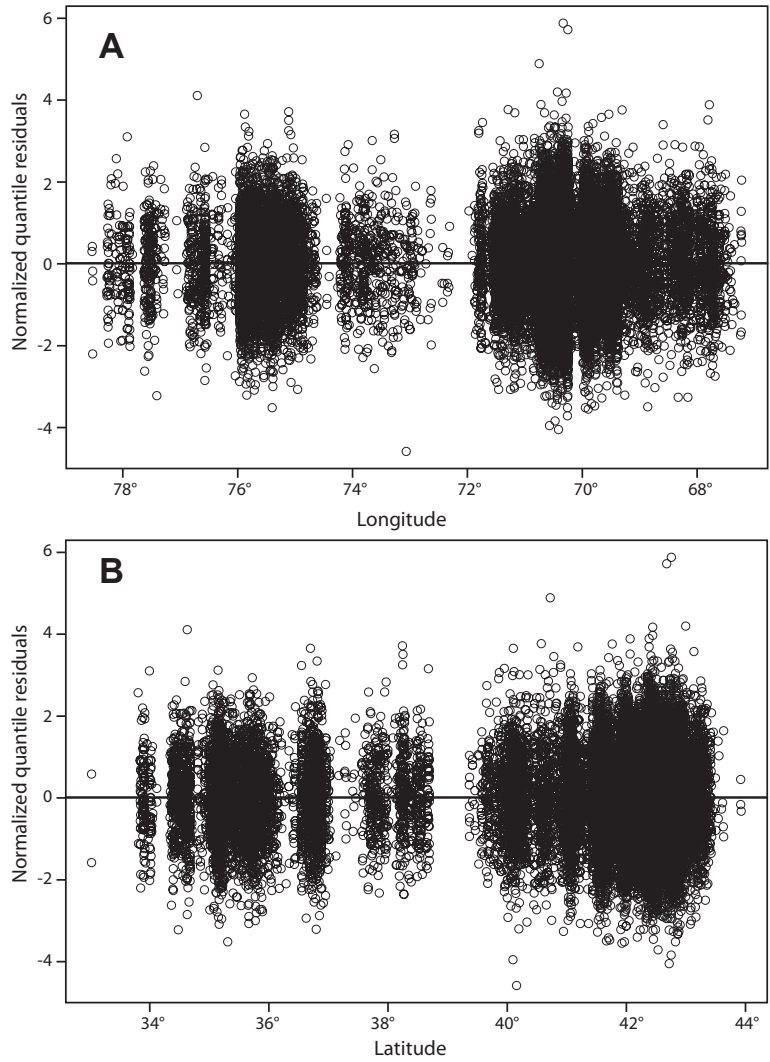

Fig. 8. Randomized quantile residuals from observed (NEFOP) predictions by (A) longitude and (B) latitude.

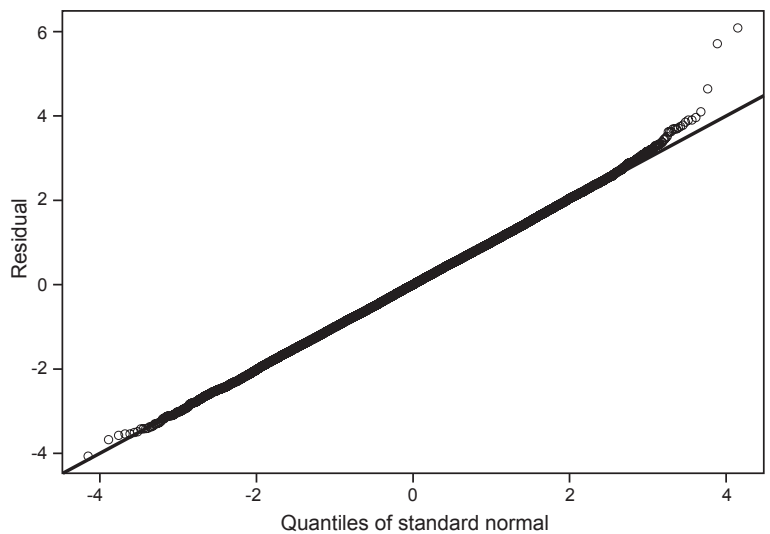

Fig. 9. QQplot of randomized quantile residuals. Note: Dunn and Smyth (1996) recommended creating at least four of these plots since the data are randomized. Only one plot is displayed here, though four plots were created, all of which looked very similar.

tours. This corresponds with previous research, which showed a mean depth of $85 \mathrm{~m}$ for harbor porpoise sightings (Hamazaki, 2002), and a preference for the $92 \mathrm{~m}$
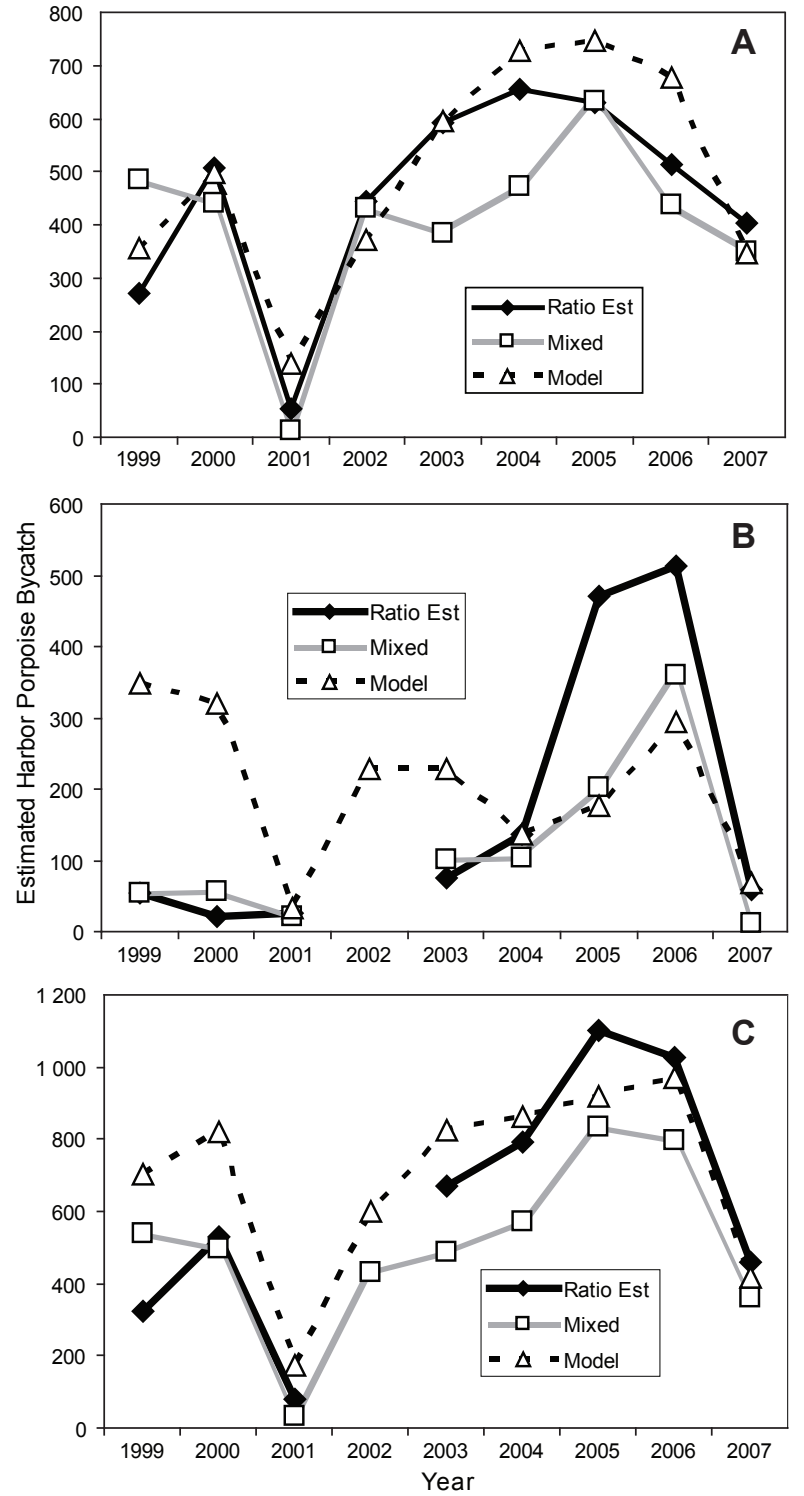

Fig. 10. The (A) Northeast, (B) Mid-Atlantic, and (C) full region, estimates for the three estimating approaches. Note differences in $y$-axes scaling in the three plots.

contour for tracked animals (Read and Westgate, 1997). The north-south seasonal movements also correspond to previous research (Palka et al., 1996; Waring et al., 2007) as seen in: (a) the limited bycatch during the summer when much of the harbor porpoise population is likely north of the primary Gulf of Maine fishing grounds off of Massachusetts, New Hampshire and Southern Maine (Fig. 2), (b) the peak bycatch in the Gulf of Maine during the autumn from October through December, and (c) the peak bycatch off of New Jersey in February, and south of New England in February and April. 
TABLE 4. CVs of the annual bycatch estimates using three different estimation approaches.

\begin{tabular}{|c|c|c|c|c|c|c|}
\hline \multirow[b]{2}{*}{ Year } & \multicolumn{3}{|c|}{ Northeast } & \multicolumn{3}{|c|}{ Mid-Atlantic } \\
\hline & $\begin{array}{c}\text { Traditional } \\
\text { Ratio CV }\end{array}$ & $\begin{array}{c}\text { Mixed } \\
\text { Variable } \\
\text { Ratio CV }\end{array}$ & Model CV & $\begin{array}{c}\text { Traditional } \\
\text { Ratio CV }\end{array}$ & $\begin{array}{c}\text { Mixed } \\
\text { Variable } \\
\text { Ratio CV }\end{array}$ & Model CV \\
\hline 1999 & 0.28 & 0.40 & 0.20 & 0.49 & 0.80 & 0.24 \\
\hline 2000 & 0.37 & 0.32 & 0.23 & 0.76 & 1.01 & 0.24 \\
\hline 2001 & 0.97 & 2.65 & 0.69 & 0.95 & 1.02 & 0.67 \\
\hline 2002 & 0.37 & 0.42 & 0.20 & unk & unk & 0.25 \\
\hline 2003 & 0.33 & 0.36 & 0.19 & 1.13 & 1.16 & 0.22 \\
\hline 2004 & 0.36 & 0.42 & 0.18 & 0.91 & 0.73 & 0.26 \\
\hline 2005 & 0.23 & 0.21 & 0.14 & 0.51 & 0.51 & 0.22 \\
\hline 2006 & 0.31 & 0.29 & 0.14 & 0.32 & 0.30 & 0.21 \\
\hline 2007 & 0.37 & 0.33 & 0.18 & 1.03 & 1.03 & 0.25 \\
\hline
\end{tabular}

TABLE 5. $P$-values of $z$-tests comparing estimates of different bycatch estimating approaches.

\begin{tabular}{cccccccc}
\hline & \multicolumn{3}{c}{ Northeast } & & \multicolumn{3}{c}{ Mid-Atlantic } \\
\cline { 2 - 3 } Year & $\begin{array}{c}\text { Traditional } \\
\text { Ratio-Est. } v s . \\
\text { Mixed }\end{array}$ & $\begin{array}{c}\text { Traditional } \\
\text { Ratio Est. } v s . \\
\text { Model }\end{array}$ & $\begin{array}{c}\text { Mixed } v s . \\
\text { Model }\end{array}$ & $\begin{array}{c}\text { Traditional } \\
\text { Ratio-Est. } v s . \\
\text { Mixed }\end{array}$ & $\begin{array}{c}\text { Traditional } \\
\text { Ratio Est. } v s . \\
\text { Model }\end{array}$ & $\begin{array}{c}\text { Mixed } v s . \\
\text { Model }\end{array}$ \\
\hline 1999 & 0.303 & 0.412 & 0.532 & & 1.000 & $0.001^{*}$ & $0.002^{*}$ \\
2000 & 0.775 & 0.967 & 0.749 & & 0.551 & $0.000^{*}$ & $0.006^{*}$ \\
2001 & 0.518 & 0.429 & 0.216 & & 0.905 & 0.812 & 0.707 \\
2002 & 0.961 & 0.685 & 0.756 & & NA & NA & NA \\
2003 & 0.387 & 0.986 & 0.238 & & 0.863 & 0.126 & 0.319 \\
2004 & 0.552 & 0.786 & 0.280 & & 0.815 & 0.994 & 0.691 \\
2005 & 0.998 & 0.519 & 0.507 & & 0.304 & 0.226 & 0.813 \\
2006 & 0.713 & 0.379 & 0.134 & & 0.435 & 0.215 & 0.606 \\
2007 & 0.779 & 0.729 & 0.982 & & 0.451 & 0.860 & $0.007^{*}$ \\
\hline
\end{tabular}

* denotes $P$-value $<0.05$

With the spatial-temporal distribution focus of the regression model, it appears that bycatch of harbor porpoise is primarily driven by the presence or absence of harbor porpoise in the region. This is not to say that gear parameters do not influence the bycatch of these animals. The inclusion of mesh size in the model dropped the AIC and the model dispersion significantly, indicating that mesh size plays a considerable role in bycatch. Harbor porpoise bycatch increased with larger mesh sizes and the same pattern has also been observed with gillnet bycatch of coastal bottlenose dolphin (Palka and Rossman, 2001) and sea turtles (Murray, 2009). In addition, looking at significant variables not available for the entire fishery in the effort datasets, extended soak time of the gear and long total gear lengths were associated with high bycatch rate, particularly in the Mid-Atlantic region.

Pinger usage has been shown to limit harbor porpoise bycatch in this, and other fisheries (Kraus et al., 1997; Larsen, MS 1999; Trippel et al., 1999; Gearin et al., 2000; Palka et al., 2008). It has therefore been incorporated in the present HPTRP (NMFS, 1998) and considered during a recent take reduction team (TRT) meeting to reduce future bycatch (NMFS, 2007b). However, when modeling the Northeast and Mid-Atlantic fisheries as a whole, pinger usage did not have a low enough AIC to be included in the model, implying pinger usage was not highly correlated to the bycatch rates in 
the entire region. This is probably due, at least in part, to the fact that pingers are not required in the Mid-Atlantic and that there was evidence of non-compliance to the pinger regulations within the Northeast fishery (Palka et $a l ., 2008)$. Even if pinger use had been included in the final model, it is difficult to accurately translate pinger use into bycatch estimates because of poor compliance with pinger regulations, and lack of pinger usage information in the total fishery effort datasets.

One goal of reassessing the harbor porpoise bycatch estimating approach was to improve estimates in the Mid-Atlantic. Past ratio estimates in the Mid-Atlantic were generally stratified by state and month or state and season so that estimated bycatch for the whole MidAtlantic region was often derived from one state-month combination, thus, the estimated bycatch from other states and months was considered to be zero (Rossman and Merrick, 1999; Belden et al., 2006; Belden and Orphanides, 2007). Compounding the difficulty of estimating bycatch in this region was that for most of the time series in consideration, the percentage of the fishery observed was low, roughly 2\% (Waring et al., 2004; Waring et al., 2007). Consequently, using the traditional strata and ratio estimation approach, Mid-Atlantic estimates often resulted in wildly fluctuating estimates. Using model based port groupings and the mesh size categories generally moderated the large inter-annual swings into more realistic year to year estimates (Fig. 10).

One apparent exception to these moderated estimates occurred with the 1999-2000 Mid-Atlantic estimates, when the model estimates were significantly different than the estimates derived from the other two approaches (Table 5, Fig. 10). The mismatch between these estimates appears to be driven primarily by the year categorization in the model, which grouped 1999, 2000, and 2003 together. Sub-areas of the Mid-Atlantic during these years were at, or near, study period highs in landings and bycatch rates, and landings were particularly large in the high bycatch rate mesh and depth categories. With limited observed bycatch in these areas, the model may have leaned too heavily on the year categorizations to calculate Mid-Atlantic estimates for these years. The impact of this did not show up in the predictions based on observer data (Fig. 6), but was seen when applied to larger than usual landings for those years. This would also help explain the markedly higher (though not significantly different) Mid-Atlantic model bycatch rate for 2003 (Table 5, Fig. 10).

Despite the differences with 1999-2000 Mid-Atlantic annual estimates, the inclusion of a categorical year vari- able in the model was necessary for predicted model results to fit the observed annual data. The categorical year variable could be necessary to account for un-modeled variability in a number of factors, including: (a) compliance with the gillnet regulations, (b) environmental factors (such as SST) which might drive inter-annual changes in the harbor porpoise or target fish movements, (c) fishery practice changes due to fish management regulations, (d) fisher's preferences, (e) changes in observer coverage, or (f) some combination of the above.

The much smaller CVs associated with the regression model based estimates at first glance suggests that the regression model approach may provide a more accurate estimate. However, adding the year variable to the model could have over-parameterized the model, resulting in false precision and artificially low CVs since it decreased the AIC by less than $2 \%$ and increased the dispersion from 3.0 to 4.0 (Table 3). Opinions about acceptable levels of dispersion vary, though Burnham and Anderson (2002) argue that dispersion parameters from one to four are acceptable and over six indicates a structural lack of fit. Since the model dispersion using a quasi-Poisson distribution was higher than would be preferred, a negative binomial model approach was also explored, but it greatly over-predicted bycatch. Regression models are likely to be over fit, particularly when dealing with rare observations and investigating a large number of variables for inclusion in the model, and can consequently loose their applicability in future years (Vaughn and Ormerod, 2005). After data are collected in future years, the robustness of the regression model can be fully evaluated, and other model types well suited to deal with over-dispersion, such as negative binomial and zero-inflated models, could be more fully explored.

Aside from model choice, a more basic and common critique of bycatch estimates are the use of landings as a unit of effort. Often times there may not be a good relationship between landings and bycatch. However, in this case, landings fit the statistical requirements for a unit of effort (statistically significant increasing bycatch with increasing effort). Another critique is that declining amounts of target species may result in more effort to land the same amount of fish, thus jeopardizing the bycatch estimate by, in essence, varying the unit of effort within the study. While this concern is valid, landings were shown to be an unbiased estimator of harbor porpoise bycatch in these fisheries when compared to soak duration, gear length, and a combination of soak duration and gear length (Rossman and Orphanides, 2009). All units of effort produced similar bycatch estimates across different sampling levels and had minimal bias 
$(<4 \%)$ when compared to true observed bycatch (Rossman and Orphanides, 2009).

Given the general convergence of estimates across approaches, it appears that all of these approaches provide satisfactory estimates. The similarity of the estimates across approaches suggests that their accuracy may be similar. However, the regression model and mixed variable ratio approaches likely provide more realistic estimates in the data poor Mid-Atlantic and offer the added advantage of processing both areas within one framework.

This study suggests that modeling fisheries bycatch can be a useful tool to investigate the reasons for bycatch and can be helpful in choosing variables to use in a ratio estimating approach. This study has also shown that investigating gear-based reasons for bycatch could help generate reasonable bycatch estimates in data poor areas or in areas on the edge of the animal's normal spatial distribution. In addition, this study has shown that if a regression model is used to estimate bycatch, care must be taken to be sure that there are enough bycatch events to provide a robust model, and that the fishery is consistent enough from year to year to have the model be applicable in future years.

\section{Acknowledgements}

First, I would like to thank the fishers, fish dealers, and observers for their reporting of fishing effort, without which bycatch estimates would not be possible. I would also like to thank all who collected, edited, and archived these mammoth datasets. Special thanks to D. Palka for her guidance and reviews during the preparation of this paper, and R. Merrick, and F. Serchuk for their helpful comments.

\section{References}

BELDEN, D. 2007. Estimates of cetacean and seal bycatch in the 2005 Northeast sink gillnet and Mid-Atlantic coastal gillnet fisheries. U.S. Dep. Commer, Northeast Fish. Sci. Cent. Ref. Doc. 07-08, 16 p. http://www.nefsc.noaa.gov/ nefsc/publications/crd/crd0708/crd0708.pdf

BELDEN D., and C. D. ORPHANIDES. 2007. Estimates of Cetacean and Pinniped Bycatch in the 2006 Northeast Sink Gillnet and Mid-Atlantic Coastal Gillnet Fisheries. U.S. Dep. Commer., Northeast Fish. Sci. Cent. Ref. Doc. 07-20, 16 p. http://www.nefsc.noaa.gov/nefsc/publications/crd/crd0720/

BELDEN D., C. D. ORPHANIDES, M. C. ROSSMAN, and D. L. PALKA. 2006. Estimates of cetacean and seal bycatch in the 2004 Northeast sink gillnet and Mid-Atlantic coastal gillnet fisheries. U.S. Dep. Commer., Northeast Fish. Sci.
Cent. Ref. Doc. 06-13, 24 p. http://www.nefsc.noaa.gov/ nefsc/publications/crd/crd0613/crd0613.pdf

BAUM, J. K., R. A. MYERS, D. G. KEHLER, B. WORM, S. J. HARLEY, and P. A. DOHERTY. 2003. Collapse and conservation of shark populations in the northwest Atlantic. Science, 299: 389-392. doi:10.1126/science.1079777

BISACK, K. D. 1993. Estimate of Total U.S. Harbor Porpoise By-Catch in the Gulf of Maine Sink Gillnet Fishery. U.S. Dep. Commer., Northeast Fish. Sci. Cent. Ref. Doc. 9311. 21 p. Available from: NOAA Fisheries, 166 Water St, Woods Hole MA 02543-1026.

1997. Harbor porpoise bycatch estimates in the New England multispecies sink gillnet fishery: 1994 and 1995. Rep. Int. Whal. Commn., 47: 705-714.

2003. Estimates of marine mammal bycatch in the Northeast (New England) multispecies sink gillnet fishery in 1996. U.S. Dep. Commer., Northeast Fish. Sci. Cent. Ref. Doc. 03-18; 21 p. http://www.nefsc.noaa.gov/nefsc/ publications/crd/crd0318/crd0318.pdf

BULL, L. S. 2007. Reducing sea bird bycatch in longline, trawl, and gillnet fisheries. Fish Fish., 8: 31-56. doi:10.1111/ j.1467-2979.2007.00234.x

BURNHAM, K. P., and D. R. ANDERSON. 2002. Model selection and multimodel inference: A practical information-theoretic approach. Springer-Verlag, New York, NY, USA, $341 \mathrm{p}$.

CASWELL H., S. BRAULT, A. J. READ, and T. D. SMITH. 1998. Harbor porpoise and fisheries: an uncertain analysis of incidental mortality. Ecol. Appl., 8: 1226-1238. doi:10.1890/10510761(1998)008[1226:HPAFAU]2.0.CO;2

CUD (Conservation and Utilization Division). 1994. Estimating harbor porpoise bycatch in the gulf of Maine sink gillnet fishery. U.S. Dep. Commer., Northeast Fish. Sci. Cent. Ref. Doc. 94-24. 5 p. Available from: National Marine Fisheries Service, 166 Water Street, Woods Hole, MA, 02543-1026.

CROWDER, L., and S. A. MURAWSKI. 1998. Fisheries bycatch: implications for management. Fisheries, 23: 8-16. doi:10.1577/15488446(1998)023<0008:FBIFM>2.0.CO;2

DIAMOND, S. L. 2003. Estimation of bycatch in shrimp trawl fisheries: a comparison of estimation methods using field data and simulated data. Fish. Bull. 101: 484-500.

DIXON, P. M., A. M. ELLISON, and N. J. GOTELLI. 2005. Improving the precision of estimates of the frequency of rare events. Ecology, 86: 1114-1123. doi:10.1890/040601

DUNN, P. K., and G. K. SMYTH. 1996. Randomized quantile residuals. J. Comput. Graph. Stat., 5: 236-244. doi: $10.2307 / 1390802$

GASKIN, D. E. 1977. Harbour porpoise, Phocoena phocoena (L.), in the western approaches to the Bay of Fundy 196975. Rep. Int. Whal. Commn., 27: 487-492.

GEARIN, P. J., M. E. GOSHO, J. L. LAAKE, L. COOKE, R. I. DELONG, and K. M. HUGHES. 2000. Experimental testing of acoustic alarms (pingers) to reduce bycatch of harbour porpoise, Phocoena phocoena, in the state of Washington. J. Cetacean Res. Manag. 2: 1-9.

HAMAZAKI, T. 2002. Spatiotemporal prediction models 
of cetacean habitats in the mid-western north Atlantic ocean (from Cape Hatteras, North Carolina, U.S.A to Nova Scotia, Canada). Mar. Mamm. Sci., 18: 920-939. doi:10.1111/j.1748-7692.2002.tb01082.x

HASTIE, T. J., and R. J. TIBSHIRANI. 1990. Generalized additive models. Chapman and Hall/CRC, Boca Raton, Florida, USA, $352 \mathrm{p}$.

JACKSON, J. B. C., M. X. KIRBY, W. H. BERGER, K. A. BJORNDAL, L. W. BOTSFORD, B. J. BOURQUE, R. H. BRADBURY, R. COOKE, J. ERLANDSON, J. A. ESTES, T. P. HUGHES, S. KIDWELL, C. B. LANGE, H. S. LENIHAN, J. M. PANDOLFI, C. H. PETERSON, R. S. STENECK, M. J. TEGNER, and R. R. WARNER. 2001. Historical overfishing and the recent collapse of coastal ecosystems. Science, 293: 629-637. doi:10.1126/science. 1059199

KRAUS, S. D., J. H. PRESCOTT, and G. S. STONE. MS 1983. Harbor porpoise, Phocoena phocoena, in the U.S. coastal waters off the Gulf of Maine: a survey to determine seasonal distribution and abundance. NMFS Contract Report, Contract No. NA82FAC00027, 22 p.

KRAUS, S. D., A. J. READ, A. SOLOW, K. BALDWIN, T. SPRADLIN, E. ANDERSON, and J. WILLIAMSON. 1997. Acoustic alarms reduce porpoise mortality. Nature, 388: 525 . doi: $10.1038 / 41451$

LARSEN, F. MS 1999. The effect of acoustic alarms on the by-catch of harbour porpoises in the Danish North Sea gill net fishery. International Whaling Commission Scientific Committee Working paper. Paper SC/51/SM41. 8 p.

LEWISON R., S. A. FREEMAN, and L. B. CROWDER. 2004. Quantifying the effects of fisheries on threatened species: the impact of pelagic longlines on loggerhead and leatherback sea turtles. Ecol. Lett., 7: 221-231. doi:10.1111/ j.1461-0248.2004.00573.x

MATTHIOPOULOS J., S., SMOUT, A. J. WINSHIP, D. THOMPSON, I. L. BOYD, and J. HARWOOD. 2008. Getting beneath the surface of marine mammal - fisheries competition. Mammal Rev., 38: 167-188. doi:10.1111/ j.1365-2907.2008.00123.x

MCCRACKEN, M. L. MS 2004. Modeling a very rare event to estimate sea turtle bycatch: lessons learned. U.S. Dep. Commer., NOAA Tech. Memo. NMFS-PIFSC-3, 25p. http://www.pifsc.noaa.gov/tech/NOAA_Tech_Memo_ PIFSC_3.pdf

MURRAY, K. T. 2007. Estimated bycatch of loggerhead sea turtles (Caretta caretta) in U.S. Mid-Atlantic scallop trawl gear, 2004-2005, and in sea scallop dredge gear, 2005. U.S. Dep. Commer., Northeast Fish. Sci. Cent. Ref. Doc. 07-04; 30 p. http://www.nefsc.noaa.gov/publications/crd/ crd0704/crd0704.pdf

2009. Characteristics and magnitude of sea turtle bycatch in U.S. Mid-Atlantic gillnet gear. Endang. Species Res., 8: 211-224.doi:10.3354/esr00211

MYERS R. A., J. K. BAUM, T. D. SHEPARD, S. P. POWERS, and C. H. PETERSON. 2007. Cascading effects of the loss of apex predatory sharks from a coastal ocean. Science, 315: 1846-1850. doi:10.1126/science.1138657

NMFS. 1998. Taking of Marine Mammals Incidental to Commercial Fishing Operations; Harbor Porpoise Take Reduction Plan Regulations. National Marine Fisheries
Service, Federal Register. 63, No. 231 (Dec. 2, 1998): 66464:66490.

2005. Recovery plan for the North Atlantic right whale (Eubalaena glacialis). National Marine Fisheries Service, Silver Spring MD, 133 p.

2006. Taking of Marine Mammals Incidental to Commercial Fishing Operations; Bottlenose Dolphin Take Reduction Plan Regulations; Sea Turtle Conservation; Restrictions to Fishing Activities; Final Rule. National Marine Fisheries Service, Federal Register. 71, No. 80 (Apr. 26, 2006): 24776:24797.

2007a. Taking of Marine Mammals Incidental to Commercial Fishing Operations; Atlantic Large Whale Take Reduction Plan Regulations; Final Rule. National Marine Fisheries Service, Federal Register. 72, No. 193 (Oct. 5, 2007): 57104:57194.

MS 2007b. Key outcomes memorandum, harbor porpoise take reduction team, December 17-19, 2007, Philadelphia, Pennsylvania. http://www.nero.noaa.gov/ prot_res/porptrp/MeetingsKeyOutcomes.html

NOAA. 2007. List of Fisheries for 2008. Department of Commerce, National Oceanic and Atmospheric Administration. Federal Register. 72, No. 227 (Nov. 27, 2007): 66048:66080.

ORPHANIDES, C. D., and D. L. PALKA. MS 2007. Landings: the Unit of Effort for Bycatch Rates in Gillnet Fishing Gear. Harbor Porpoise Take Reduction Team (HPTRP) Meeting Materials. Binder Document 3d. Available from National Marine Fisheries Service, Northeast Regional Office, 55 Great Republic Drive, Gloucester, Massachusetts, 01930-2298.

PALKA, D. 1995a. Influences on spatial patterns of Gulf of Maine harbor porpoises. In: A. S. Blix, L. Walloe and O. Ulltang (eds.). Whales, Seals, Fish and Man. Elsevier Science, New York, NY, p. 69-75.

1995b. Abundance estimate of Gulf of Maine harbor porpoise. Rep. Int. Whal. Commn. (Special Issue). 16: 27-50.

PALKA, D. L, M. C. ROSSMAN, A. S. VANATTEN and C. D. ORPHANIDES. 2008. Effect of pingers on harbour porpoise (Phocoena phocoena) bycatch in the US Northeast gillnet fishery. J. Cetacean Res. Manage., 10: 217-226.

PALKA, D. L., A. J. READ, and D. W. JOHNSTON. 1996. Summary of current knowledge of harbour porpoises in US and Canadian Atlantic waters. Rep. Int. Whal. Commn. 46: 559-565.

PALKA, D. L., and M. C. ROSSMAN. 2001. Bycatch estimates of coastal bottlenose dolphin (Tursiops truncatus) in U.S. Mid-Atlantic gillnet fisheries for 1996 to 2000. U.S. Dep. Commer., Northeast Fish. Sci. Cent. Ref. Doc. 01-15; 77 p. http://www.nefsc.noaa.gov/publications/crd/crd0115/0115.pdf

READ, A. J., P. DRINKER, and S. NORTHRIDGE. 2006. Bycatch of marine mammals in U.S. and global fisheries. Conserv. Biol., 20: 163-169. doi:10.1111/j.15231739.2006.00338.x

READ, A. J., and A. J. WESTGATE. 1997. Monitoring the movements of harbour porpoises (Phocoena phocoena) with satellite telemetry. Mar. Biol., 130: 315-322. doi:10.1007/s002270050251 
REEVES, R. R., T. D. SMITH, and E. A. JOSEPHSON. 2007. Near-annihilation of a species: right whaling in the North Atlantic.In: S.D. Kraus and R. M. Rolland(eds.). The Urban Whale: North Atlantic Right Whales at the Crossroads. Harvard University Press, Cambridge, MA, p. 39-74.

ROSSMAN, M. C., and R. L. MERRICK. 1999. Harbor porpoise bycatch in the Northeast multispecies sink gillnet fishery and the Mid-Atlantic coastal gillnet fishery in 1998 and during January-May 1999. U.S. Dep. Commer., Northeast Fish. Sci. Cent. Ref. Doc. 99-17, 36 p. http:// www.nefsc.noaa.gov/publications/crd/crd9917.pdf

ROSSMAN M. C., and C. D. ORPHANIDES. 2009. Evaluating Bias When Estimating Small Cetacean Bycatch Rates in Gillnet Fisheries Using Different Units of Effort. In: $18^{\text {th }}$ Biennial Conference on the Biology of Marine Mammals Abstracts. Society for Marine Mammalogy, Quebec City, Canada. 12-16 Oct. 2009, p. 222-223.

SMITH, T. D., D. PALKA, K. BISACK, and G. DINARDO. 1991. Preliminary Estimates of Harbor Porpoise Abundance and By-Catch. U.S. Dep. Commer, Northeast Fish. Sci. Cent. Ref. Doc. 91-04. Available from: National Marine Fisheries Service, 166 Water Street, Woods Hole, MA, 02543-1026.

TRIPPEL, E. A., M. B. STRONG, J. M TERHUNE, and D. CONWAY. 1999. Mitigation of harbour porpoise (Phocoena phocoena) by-catch in the gillnet fishery in the lower Bay of Fundy. Can. J. Fish. Aquat. Sci., 56: 113-123. doi:10.1139/cjfas-56-1-113

VAUGHN, I. P., and S. J. ORMEROD. 2005. The continuing challenges of testing species distribution models. J. Appl. Ecol., 42: 720-730. doi:10.1111/j.13652664.2005.01052.x

WARDEN, M. L., and C. D. ORPHANIDES. 2008. Preparation of the Northeast Fisheries Observer Program gillnet data for use in bycatch analyses of protected species. U.S. Dep. Commer., Northeast Fish. Sci. Cent. Ref. Doc. 0817; 44 p. http://www.nefsc.noaa.gov/publications/crd/ $\operatorname{crd} 0817 /$

WARING, G. T, E. JOSEPHSON, C. P. FAIRFIELD-WALSH, and K. MAZE-FOLEY, editors. 2007. U.S. Atlantic and Gulf of Mexico Marine Mammal Stock Assessments 2007. NOAA Tech Memo. NMFS NE 205; 415 p. http:// www.nefsc.noaa.gov/publications/tm/tm205/tm205.pdf

WARING ,G. T., R. M. PACE, J. M. QUINTAL, C. P. FAIRFIELD, and K. MAZE-FOLEY (Eds.). 2004. US Atlantic and Gulf of Mexico marine mammal stock assessments - 2003. U.S. Dep. Commer., NOAA Tech Memo. NMFS NE 182; 287 p. http://www.nefsc.noaa. gov/publications/tm/tm182/tm182.pdf

WIGLEY, S.E., P.HERSEY, and J.E.PALMER. 2008. Adescription of the allocation procedure applied to the 1994 to 2007 commercial landings data. U.S. Dept. Commer, Northeast Fish. Sci. Cent. Ref. Doc. 08-18; 61 p. http://www.nefsc. noaa.gov/publications/crd/crd0818/crd0818.pdf 